UCRL-ID-120930

\title{
Terminal Ballistic Experiments for the Development of Turbine Engine Blade Containment Technology
}

\author{
R. P. Gogolewski \\ B. J. Cunningham
}

January 25, 1995

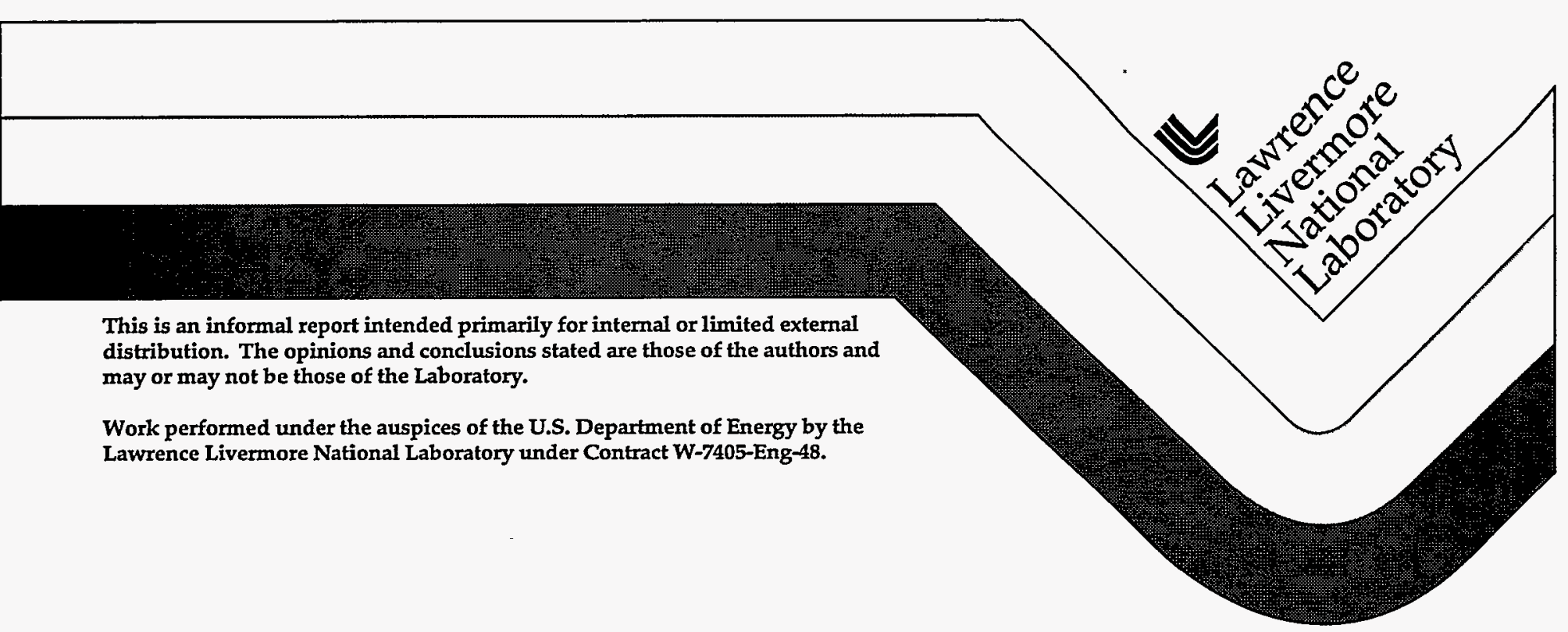


This document was prepared as an account of work sponsored by an agency of the United States Government. Neither the United States Government, nor the University of California, nor any of their employees makes any warranty, express or implied, or assumes any legal liability or responsibility for the accuracy, completeness, or usefulness of any information, apparatus, product, or process disclosed, or represents that its use would not infringe privately owned rights. Reference herein to any specific commercial products, process, or service by trade name, trademark, manufacturer, or otherwise, does not necessarily constitute or imply its endorsement, recommendation, or favoring by the United States Government or the University of California. The views and opinions of authors expressed herein do not necessarily state or reflect those of the United States Government or the University of California, and shall not be used for advertising or product endorsement purposes.

This document has been reproduced directly from the best available copy.

Available to DOE and DOE contractors from the Office of Scientific and Technical Information P.O. Box 62 , Oak Ridge, TN 37831

Prices available from (615) 576-8401, FTS 626-8401

Available to the public from the National Technical Information Service

U.S. Department of Commerce 5285 Port Royal Road Springfield, VA 22161 


\section{DISCLAIMER}

Portions of this document may be illegible in electronic image products. Images are produced from the best available original document. 


\section{Contents}

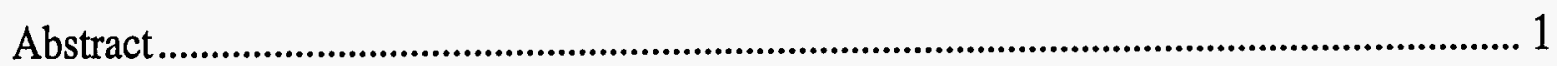

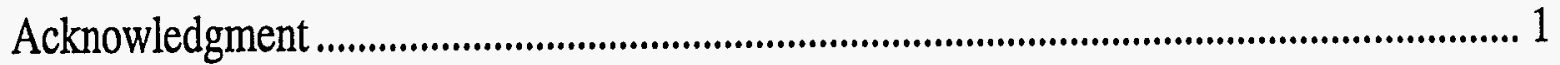

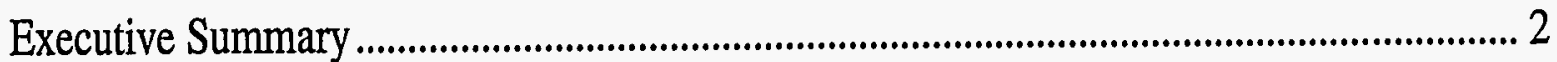

Technical Discussion ............................................................................................................. 4

Ballistic Experiments with Annealed Titanium Plates ........................................................ 4

Ballistic Experiments with Aluminum and Titanium Single Plates and Laminates...... 12

Ballistic Experiments and Geometric Scaling .............................................................. 21

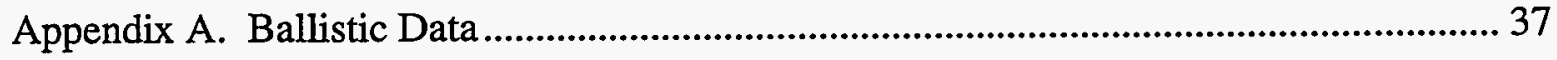

Appendix B. Estimate of Ballistic Limit Speeds ................................................................. 41

Appendix C. A Simple Model for Thin-Plate Shear-Plug Failure ........................................ 43 


\title{
Terminal Ballistic Experiments for the Development of Turbine Engine Blade Containment Technology
}

\author{
Raymond P. Gogolewski \\ Bruce J. Cunningham
}

\begin{abstract}
The ballistic experiments reported herein were conducted in three sets between October 1993 and November 1994. The first set of experiments examined the ballistic failure of annealed titanium plates. These experiments were performed in a manner consistent with earlier experiments conducted at United Technologies' Pratt \& Whitney Division. The second set of experiments examined the ballistic performance of select aluminum and titanium alloys in single-plate and laminate form. In both sets of experiments, the failure modes of the targets were observed and catalogued. The third set of experiments evaluated underlying issues associated with geometric scaling. Blunt .30and .50-caliber hard steel projectiles impacted on geometrically similar annealed titanium plates.
\end{abstract}

\section{Acknowledgment}

This project was performed as part of the DOE/LLNL CRADA on Laminated Metal Composites for Aerospace Applications under the direction of Dr. Donald R. Lesuer, Program Manager. The authors appreciate the instructive discussions with and the perspectives offered by Mr. Craig Musson and Mr. David Alexander of United Technologies' Pratt \& Whitney Division over the course of the project. 


\section{Executive Summary}

Three sets of ballistic experiments were conducted between October 1993 and November 1994. The first set examined the ballistic failure of annealed titanium plates. These experiments were performed in a manner consistent with earlier experiments conducted at United Technologies' Pratt \& Whitney Division. For these experiments, Pratt \& Whitney supplied LLNL with copper-jacketed, hard-steel projectiles (right circular cylinders $0.30 \mathrm{in}$. in diameter and $0.82 \mathrm{in}$. long). Titanium plates of four thicknesses, ranging from 0.066 to $0.176 \mathrm{in}$. , were ballistically evaluated to determine critical projectile velocities (limit velocities).

Critical projectile velocities ranged from 685 to $1202 \mathrm{ft} / \mathrm{s}$. Post-experiment evaluation of the titanium plates revealed that, near the projectile threshold speeds, the two thickest plates failed by plugging, and the thinnest plate failed by petaling. The next-to-thinnest plate failed in a mixed plug/petal (transition) mode. The ballistic data and the modes of plate failure agreed well with those recorded by Pratt \& Whitney.

The second set of experiments examined the ballistic performance of two standard aluminum alloys, a discontinuously reinforced aluminum (DRA) alloy, an LLNLcreated 19-layer DRA/aluminum laminate, and pure and alloyed titanium in singleplate and laminate form. The ballistic data were compared to those of standard aluminum and titanium alloys known for their usefulness as armor materials. These experiments were performed using the same projectiles used during the first set.

The critical projectile velocity for the 6061-T6 aluminum alloy target agreed well with data provided by Pratt \& Whitney. Both the single plates of 7075-T6 alloy aluminum and the $6090 \mathrm{SiC}$ DRA alloy performed as well as the single-plate titanium $6 \mathrm{Al}-4 \mathrm{~V}$ alloy (at the same target areal density). Because of its inherent brittleness (elongation to failure of $3 \%$ ), the 6090 DRA alloy was the only aluminum alloy to undergo rear-surface spall adjacent to the projectile cavity.

An LLNL-created 19-layer aluminum laminate consisting of alternating layers of metallurgically bonded $6090 \mathrm{SiC}$ DRA and 5182 aluminum alloys produced a projectile critical velocity comparable to that of 6061T6 aluminum alloy. A single experiment was performed with a specially prepared aluminum laminate composed of the same two aluminum alloys, except that the central rectangular region was not bonded; the "picture frame" of 19 layers around the central rectangular region remained bonded, however. The impact speed of the projectile was just under $1300 \mathrm{ft} / \mathrm{s}$. The laminate was not perforated. The impact speed of the projectile was above the critical projectile velocity associated with the metallurgically bonded 19-layer laminate $(1267 \mathrm{ft} / \mathrm{s})$.

The total areal density for a three-plate target of 6061-T6 aluminum was about the same as for a single plate, and its ballistic performance was more than $200 \mathrm{ft} / \mathrm{s}$ higher-a substantial improvement in protection. Disassembly of the target after experiment showed that successive plates underwent progressively more stretching and deformation. The back (third) plate displayed the greatest "coning," with slight cracking directly adjacent to the projectile cavity.

Performance of a triple plate of 7075-T6 aluminum alloy was slightly inferior to that of a single plate of the same areal density. Large fractures radiated from the impact location on each plate of the target. Heattreated triple plates of the $6090 \mathrm{SiC}$ DRA after ballistic impact appeared qualitatively similar to the 7075-T6 plates.

Projectile limit velocity against the LLNL 19-layer laminates was between those of the single-plate 6061-T6 and 7039-T6 aluminum alloy targets. The laminates show a progressive increase in deformation near the impact site with successive plates. The 
ballistic performance of the triple-plate 5182 aluminum alloy was equal to that of the triple-plate 6061-T6 aluminum alloy. Near perforation, the 5182 aluminum underwent significant stretching and exhibited the highest elongation to failure (25\%) of any of the alloys evaluated.

The ballistic performances of the Grade 4 pure and $6 \mathrm{Al}-4 \mathrm{~V}$ alloy titanium triple plates were better than those of their singleplate counterparts. However, the extent of local deformation of the titanium plates near impact is significantly less than observed for the 6061-T6 and 5182 aluminum alloy triple plates. The improvement of the triple-plate titanium targets is corresponding less dramatic than for the triple-plate aluminum.

It appears that the distinction between superior single- and multi-plate ballistic performance may be driven by the tradeoff between inherent strength and ductility of the materials. Two extremes exist: one of very high tensile (and shear) strength with little ductility (elongation to failure); the other of low tensile strength and large ductility. The former may perform better in single-plate form; the latter may perform better in multi-plates.

The third set of experiments evaluated underlying issues associated with geometric scaling. Identical terminal-ballistic experiments were performed at two geometric scales. Blunt .30- and .50-caliber Ti 6Al-4V alloy and hard steel projectiles were fired at two different thickness of $\mathrm{Ti} 6 \mathrm{Al}-4 \mathrm{~V}$ alloy single-plate targets.

Over the range of impact speeds tested, the projectiles behaved essentially as rigid bodies during target penetration. At the highest impact speeds, the projectile noses showed modest deformation. Examination of the target plates after the experiments revealed that, near the projectile critical speeds, the .30-caliber-scale thinner target plates failed in the petal mode. This occurred when the plates were impacted by steel and by titanium projectiles. At the .50 -caliber scale, the corresponding thinner targets impacted by steel projectiles failed in the plug mode; the plates impacted by titanium projectiles failed in a plug or mixed (transition) mode. The failure mode of the targets changed with scale.

The thicker target plates impacted by steel projectiles failed in the plug mode at both scales. Experiments were not performed with the titanium projectiles impacting the thicker titanium targets, because the estimate of critical projectile speed was greater than $2000 \mathrm{ft} / \mathrm{s}-$ not in the range of impact speeds of interest.

By using conclusions drawn from a simple analytical model for the shear-plug failure of thin plates, the differences between the LLNL-derived critical projectile speeds for 5.2-g hard steel and 2.95-g titanium projectiles and the Pratt \& Whitney data for 6.8-g, .30-caliber, copper-jacketed, hard steel projectiles of similar core geometry were reconciled. Furthermore, the .50-caliber LLNL data were compared with "perfectly scaled" .30-caliber data.

In nondimensional form, all data generated by LLNL and by Pratt \& Whitney were compared easily. Changes in target failure mode became quite apparent. Geometric scaling is valid when the target failure mode is independent of scale, given that projectile and target materials do not change with scale and that the experiments are performed the same way. When the target failure mode changes, when different materials are evaluated, or when the experimental conditions are changed, geometric scaling is not expected to be valid. 


\section{Technical Discussion}

Three sets of ballistic experiments were conducted for this project between October 1993 and November 1994. The first set, performed in a manner consistent with earlier experiments conducted at United Technologies' Pratt \& Whitney Aircraft Division, examined the ballistic failure of annealed titanium plates. The second set examined the ballistic performance of select aluminum and titanium alloys in single-plate and laminate form. In both sets of experiments, the failure modes of the targets were observed and catalogued. The third set of experiments examined the underlying issues and the validity of geometric scaling. Blunt .30- and .50-caliber hard steel projectiles impacted on geometrically similar annealed titanium target plates.

\section{Ballistic Experiments with Annealed Titanium Plates}

In the experiments, each plate was 3.25 in. square and was composed of fully annealed 6Al$4 \mathrm{~V}$ titanium alloy. The chemical composition and select mechanical properties of the titanium alloy (as provided by the Titanium Metals Corporation of Morristown, Tennessee) are listed in Table 1, along with average plate thickness and hardness as measured by LLNL personnel.
The projectiles used for the terminal ballistic experiments were copper-jacketed, hard-steel, right circular cylinders approximately $.30 \mathrm{in}$. in diameter and 0.82 in. long. Each projectile weighed about $6.8 \mathrm{~g}$. Figure 1 shows details of the projectile design. The projectiles were provided by the Pratt \& Whitney Division of United Technologies Corporation.

Figure 2 illustrates the experimental setup. Projectiles were launched from a rifled .30-caliber gun with a barrel 24 in. long. An ullage filler was fabricated to reduce breech volume. Each titanium target plate was mounted between two plates; the mounting bolts, which held the plates together, were tightened only enough to keep the target plate in position. A foil switch and delays were used to successively trigger two $150-\mathrm{kV} \mathrm{x}$ rays. The radiographs were used to monitor projectile pitch and to measure projectile speed just prior to target impact. A 0.75-in.-thick 6061T6 aluminum alloy plate served as a witness plate.

Prior to the ballistic experiments, load development experiments were conducted. Initially, relatively large shot-to-shot velocity variations for a fixed powder load were experienced due to excessive and variable levels of resistance between the projectiles' copper jackets

Table 1. Titanium plates.

\begin{tabular}{|c|c|c|c|c|}
\hline & & al Con & osition & \\
\hline & & & $89.65 \%$ & \\
\hline & & & $6.00 \%$ & \\
\hline & & & $4.00 \%$ & \\
\hline & & & $0.25 \%$ & \\
\hline & & & $0.08 \%$ & \\
\hline & & & $0.03 \%$ & \\
\hline $\begin{array}{l}\text { Plate thickness } \\
\text { (in.) }\end{array}$ & $\begin{array}{c}\sigma_{\mathrm{y}} \\
(\mathrm{ksi})\end{array}$ & $\begin{array}{c}\sigma_{\mathrm{u}} \\
(\mathrm{ksi})\end{array}$ & $\begin{array}{c}\text { Elongation } \\
(\%)\end{array}$ & $\begin{array}{c}\text { Hardness } \\
\text { (Rockwell-c) }\end{array}$ \\
\hline 0.066 & 143 & 153 & 12 & 38 \\
\hline 0.083 & 137 & 145 & 14 & 32 \\
\hline 0.128 & 136 & 142 & 16 & 36 \\
\hline 0.176 & 134 & 141 & 17 & 34 \\
\hline
\end{tabular}




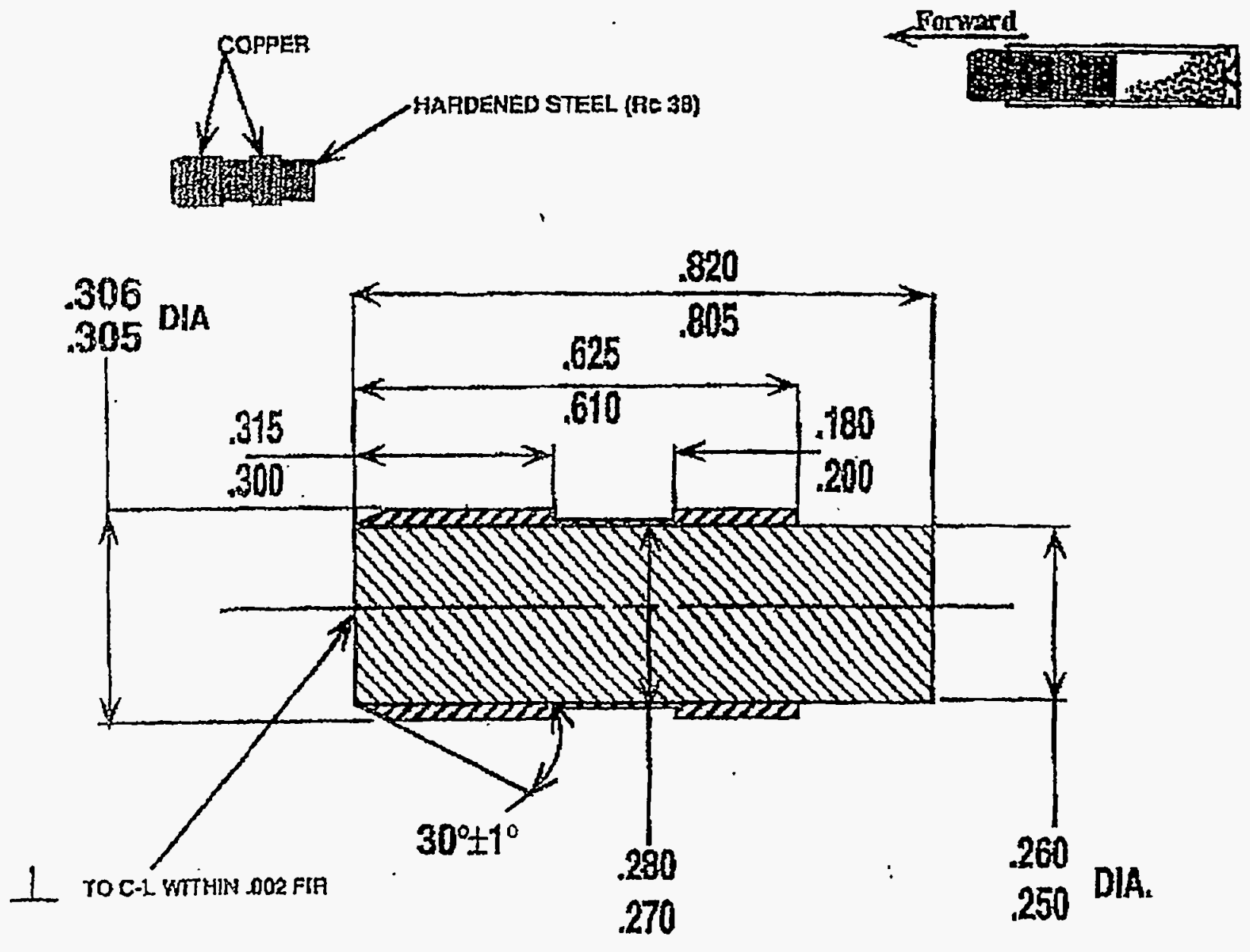

Figure 1. Cross section of the copper jacketed hard steel projectile used in the experimental series. Supplied by Pratt \& Whitney.

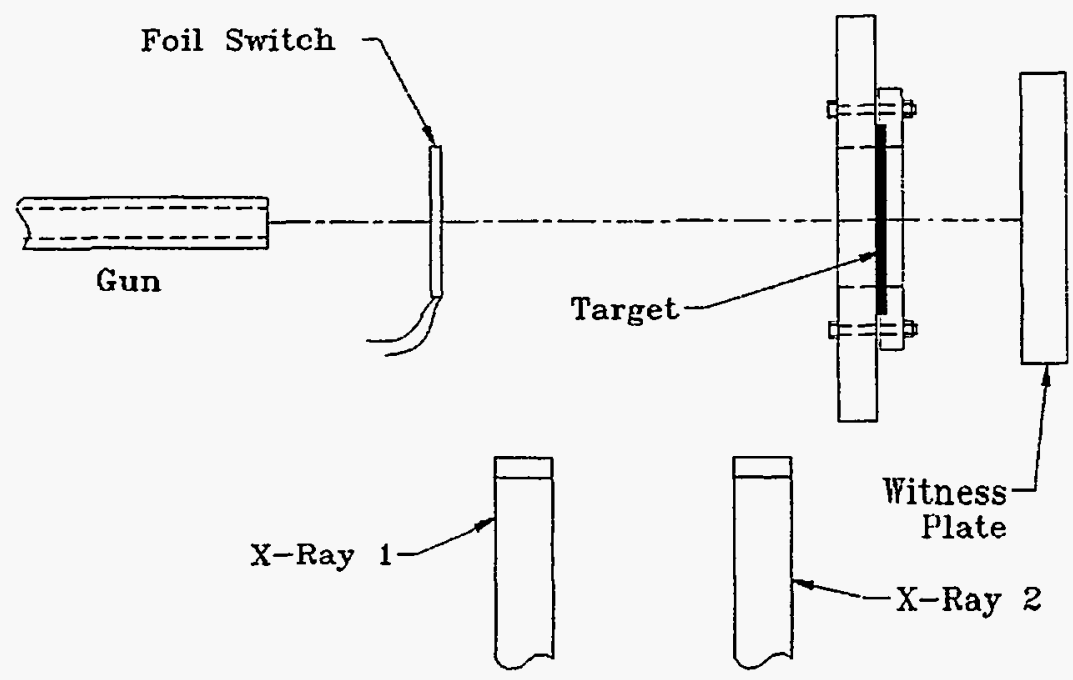

Figure 2. Experimental setup. When perforated, the foil switch activates delays which trigger $x$ ray (1) and then (2). 
and the gun rifling. Reducing the projectile (jacket thickness) diameter to 0.302 in. produced more consistent projectile velocities.

In Appendix A, Table A1 provides details of each ballistic experiment conducted (experiments SST-23 through SST-34). Projectile pitch over the set of experiments was measured to be within $1.3^{\circ}$, except for a pitch of $4.4^{\circ}$ measured for the projectile prior to target impact during experiment SST-31. On this basis, data derived from the set of experiments are considered ballistically valid, except for SST-31, which is suspect. In Appendix B, Table B1, the value under the heading "Estimate of limit velocity" is either (1) an estimate based on the average projectile velocity derived from two experiments-one in which the projectile just fails to pass through the target and the other in which the projectile just perforates the target, or (2) the recorded projectile velocity derived from an experiment in which, by examination of the target after the experiment, the projectile velocity was judged to be slightly below the limit velocity. In the experiments for which estimate (2) was applied, it was judged that additional experiments were not required. In one experiment, the titanium plate was perforated, but the projectile remained lodged within the target, as shown in Fig. 3. In another experiment, the projectile almost passed through the target,
Figure 3. Edge photo of a projectile that was captured by the target after perforating it by plugging.

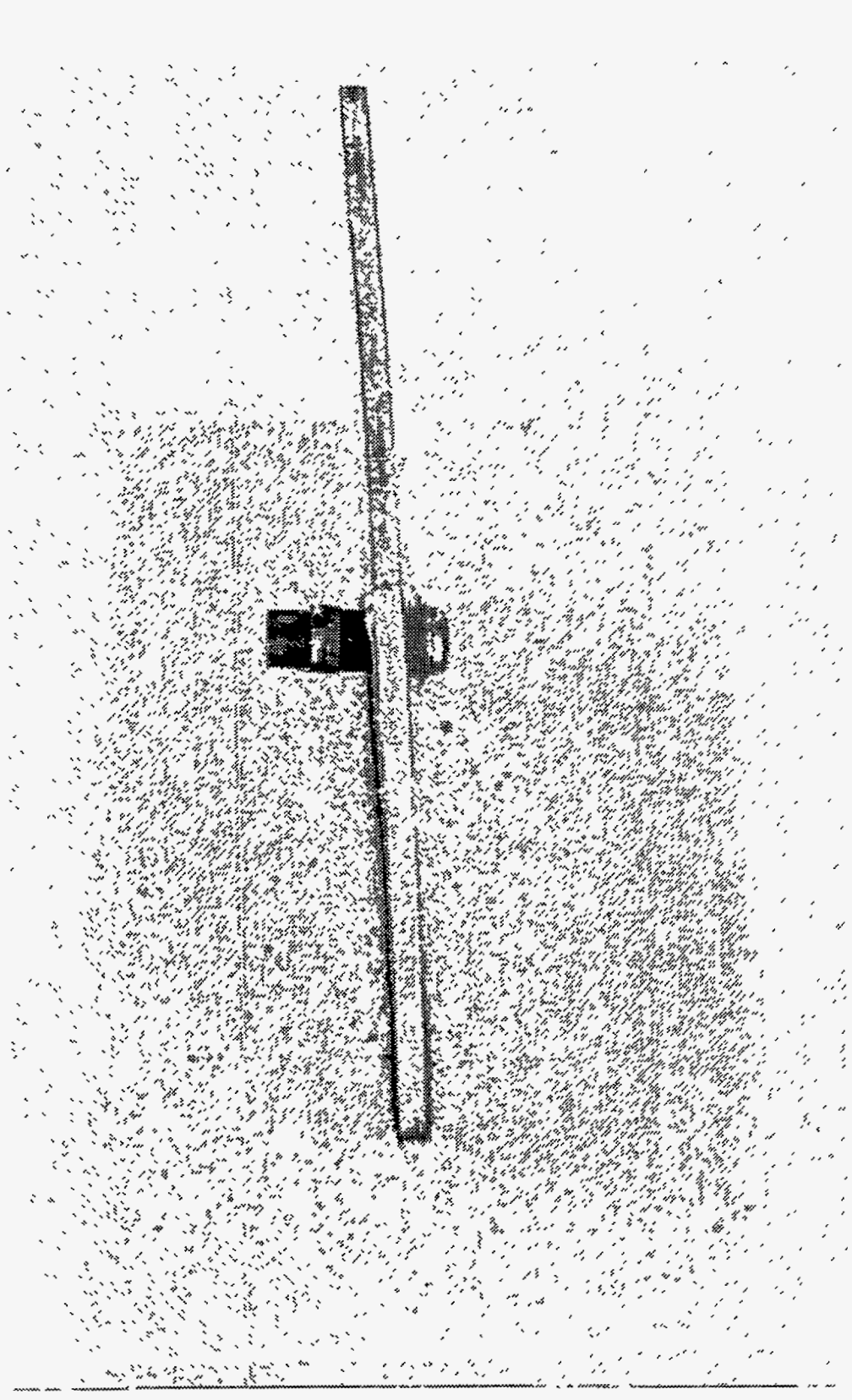


stopped, and bounced backwards, as shown in Fig. 4. Limit velocities in Appendix B that are based on estimate (2) are noted with a (+).

Figure 5 displays the LLNL ballistic limit speeds superimposed on the Pratt \& Whitney "just contained" summary data. We think that the data are in good agreement. Figure 6 displays individual LLNL ballistic data also superimposed on the P\&W data. Here, closed symbols represent data based on projectiles perforating titanium plates; open symbols represent data based on projectiles not passing through titanium plates.

Post-test examination of the titanium plates revealed that, near the projectile threshold speeds, the two thickest plates failed by plugging and the thinnest plates petaled. The next-tothinnest plates appeared to fail by a combination of plugging and petaling (see Fig. 7).

Figures 8 and 9 display plastic strain contours generated by DYNA 2D for a 0.26 -in.diameter steel projectile impacting an aluminum plate at 330 and $985 \mathrm{ft} / \mathrm{s}$, respectively.* The projectiles have traveled the same distance after impacting the target (hence, the strain contours are at different times after impact). The distinctly different strain patterns and target plate shapes illustrate why the failure mode of a thin plate is a function of projectile impact speed. At low projectile speeds, the plate has sufficient time to respond as a whole - the plate bends, failure originates off-axis on the side opposite the impact, and tears progress radially outward-i.e., a petaling failure. At higher projectile impact speeds, there is less time for the plate to respond as a whole, plate damage is more localized, and consequently plugging failure occurs. In this target-plate failure mode, the projectile acts much like a punch.

* The computational physics analysis leading to the results displayed in Figs. 8 and 9 was performed by John Reaugh, LLNL Physics and Space Technology Directorate.

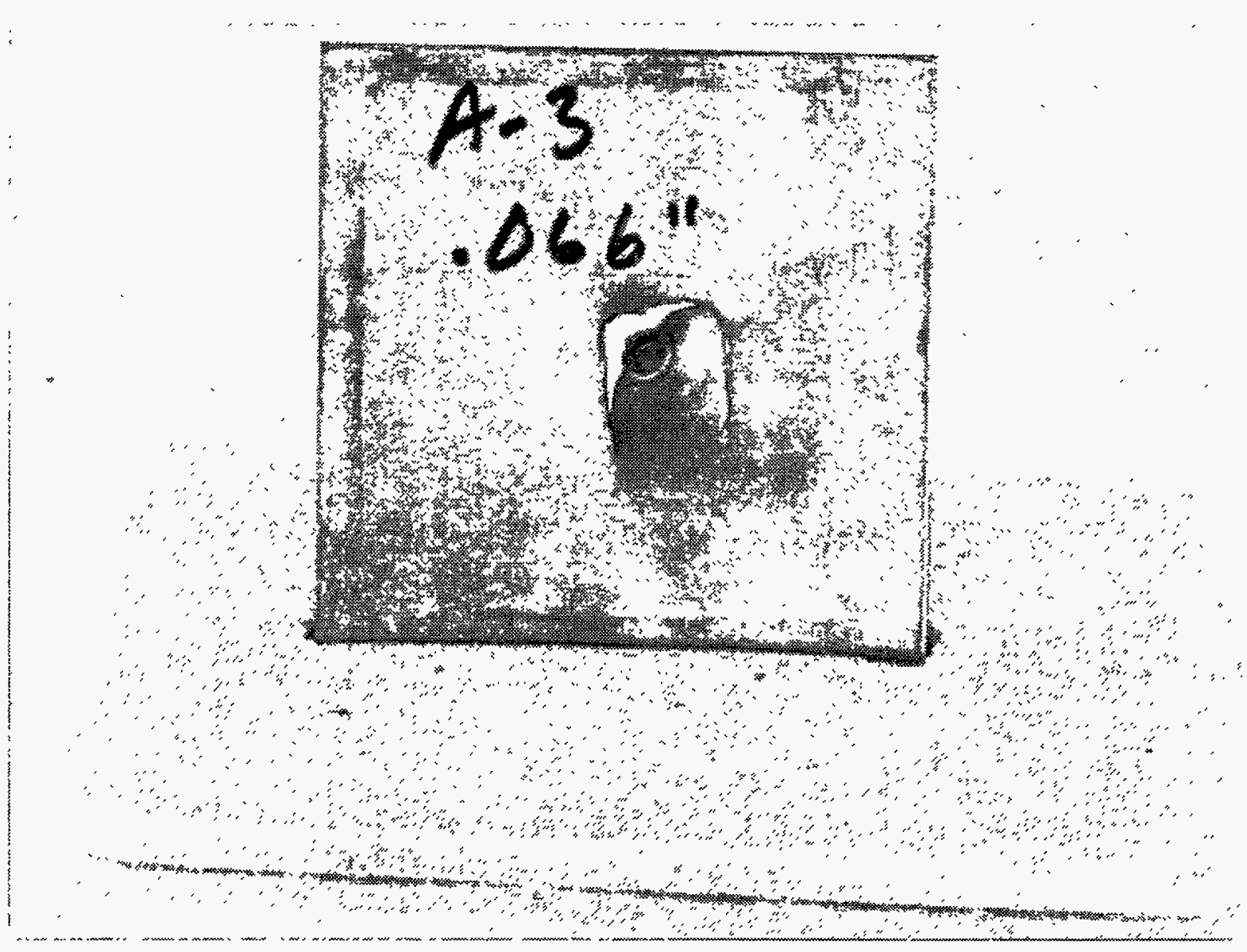

Figure 4. In this experiment, the projectile perforated the target, passed almost entirely through it, and then bounced backward. Here, the target failed in petaling mode. 


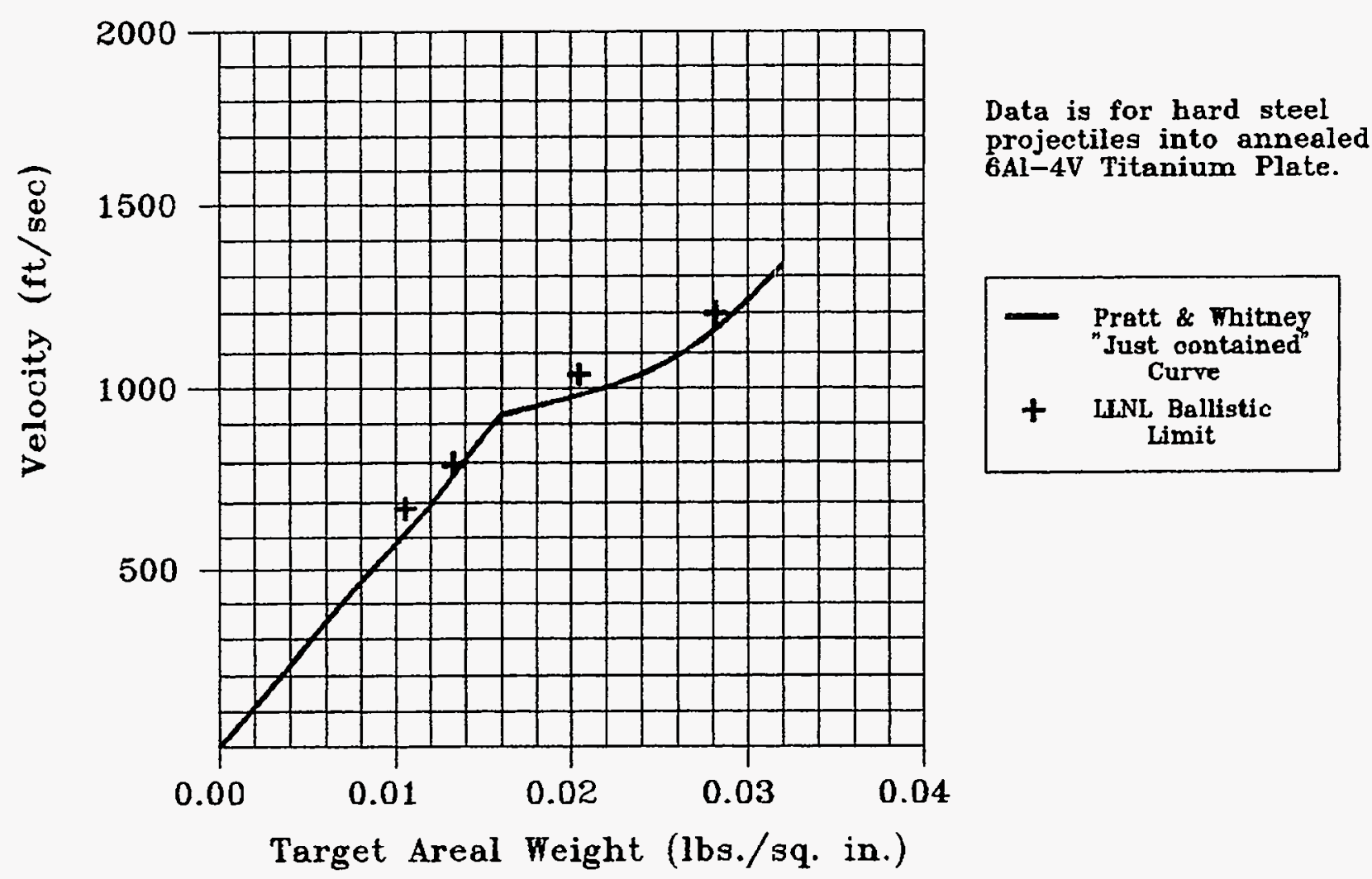

Figure 5. Comparison of LLNL's estimate of the ballistic limit and Pratt \& Whitney data.

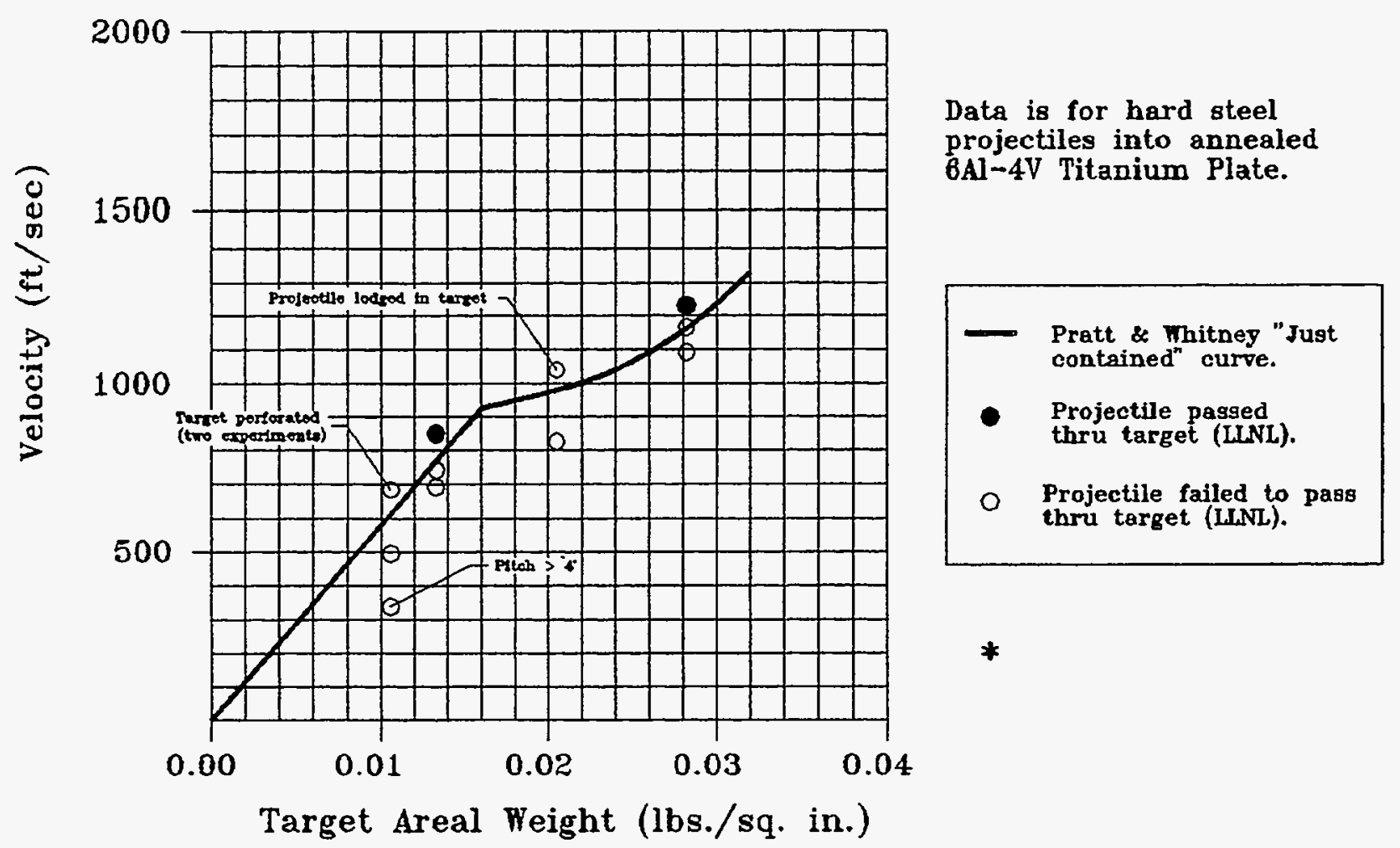

Figure 6. LLNL individual shot data plotted with Pratt \& Whitney's "Just Contained" curve. 


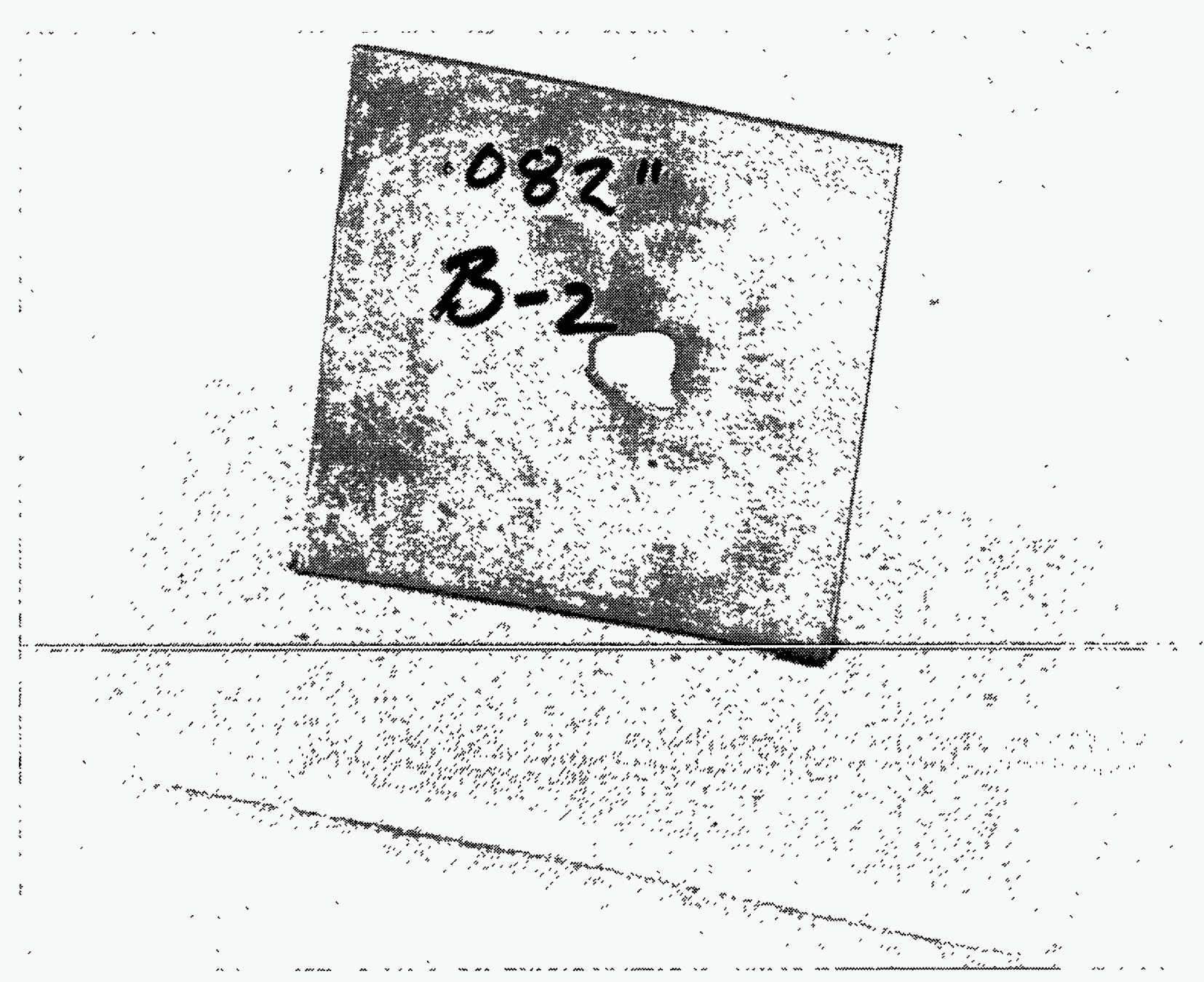

Figure 7. Target showing transitional plugging/petaling failure. 


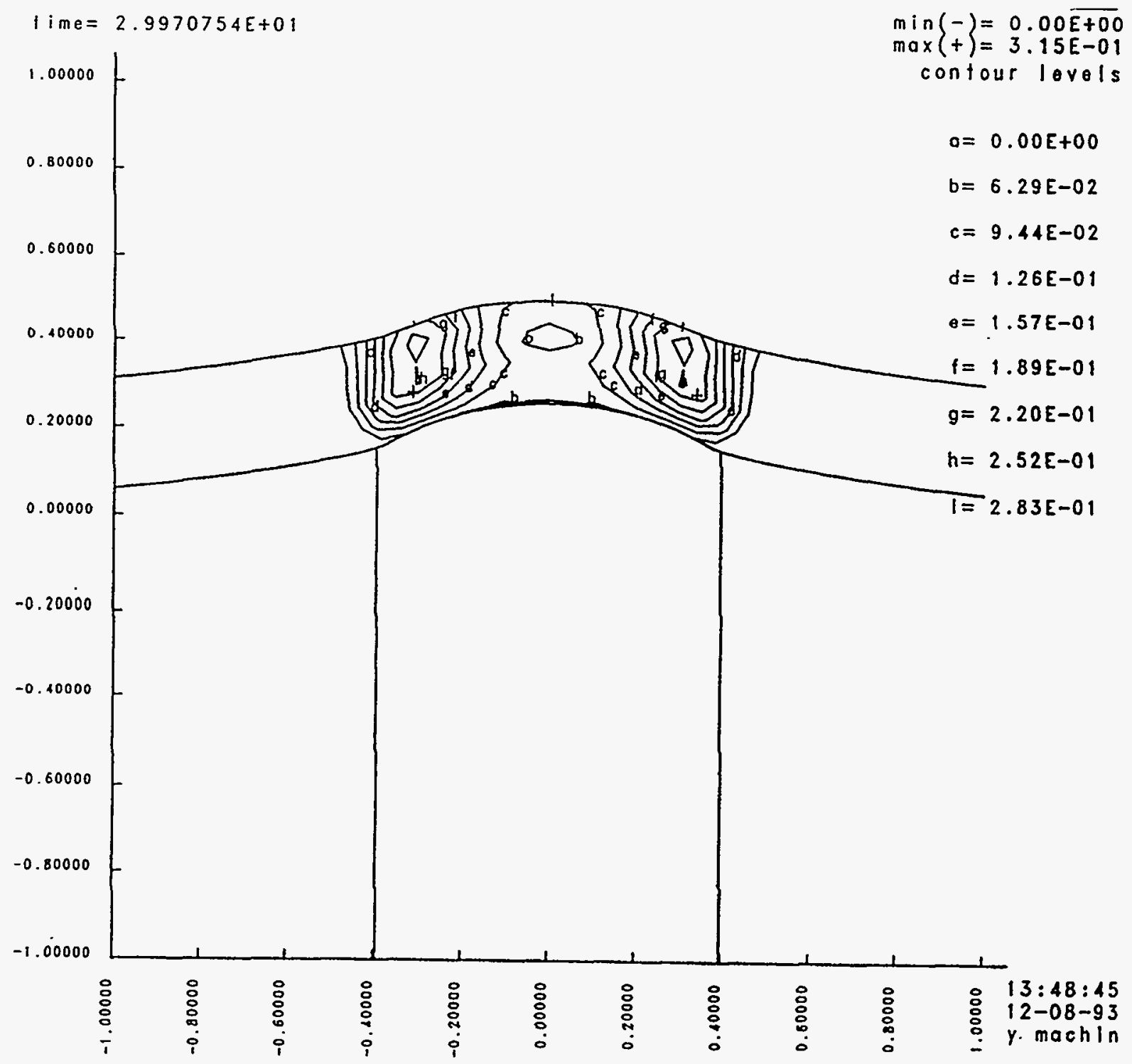

Figure 8. DYNA-2D Computer simulation showing strain contours for a 0.26-in.-diameter hard steel projectile impacting a 0.8 -in.-thick aluminum plate at $330 \mathrm{ft} / \mathrm{s}$. 


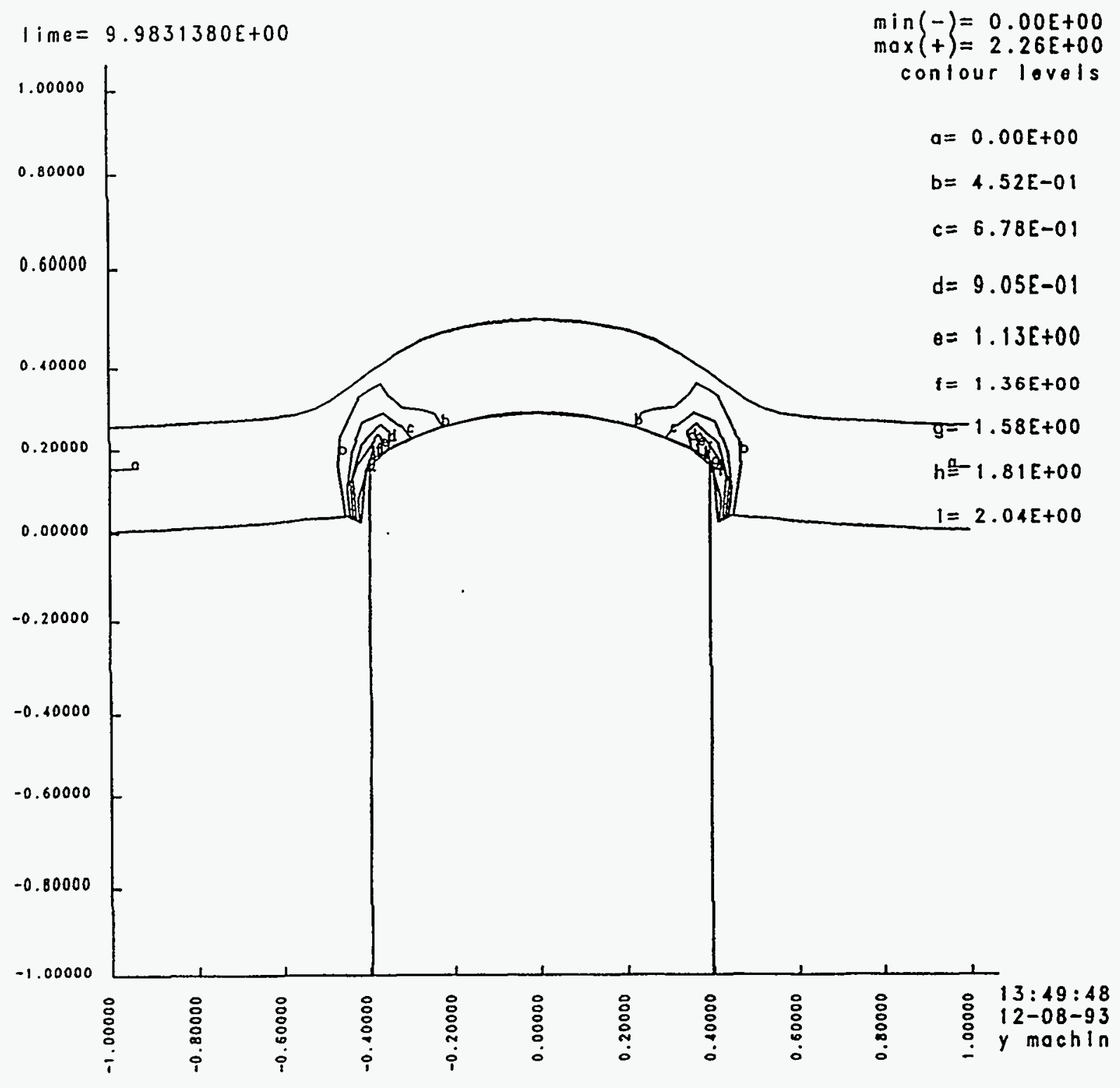

Figure 9. Projectile/target combination shown in Fig. 8 with a projectile impact velocity of $990 \mathrm{ft} / \mathrm{s}$. The projectile has traveled the same distance after initial impact as in Fig. 8. Note the difference in location of the strain concentrations and in overall target shape. 


\section{Ballistic Experiments with Aluminum and Titanium Single Plates and Laminates}

In this series of ballistic experiments, we evaluate two standard aluminum alloys, a discontinuously reinforced aluminum (DRA) alloy, an LLNL DRA/aluminum laminate, and pure and alloyed titanium in single-plate and laminate forms. The ballistic performance of the aluminum and titanium materials is compared to that of standard alloys known for their usefulness as armor materials. Target geometry consisted of a single metallic plate 3.25 in. square or a stack of three plates, without bonding, with the same form as the single plates. Plate thickness was selected on the basis of the objectives of the experiments. In some cases, experiments were performed with heat-treated and as-received samples of the same materials.

Table 2 lists the yield strength, ultimate tensile strength, and elongation at tensile failure of alloys of interest. The aluminum alloys tend to have relatively low to intermediate values in ulimate tensile strength and a wide range of values for elongation at failure. The titanium materials have relatively high ultimate tensile strengths and intermediate values of elongation at failure.

We used the same .30-caliber, copperjacketed, steel (Rockwell-c38) projectiles given to us by Pratt \& Whitney for all of the experiments in this series (see Fig. 1). Figure 10 is a sketch of the target holder. In mounting, target plates are inserted between the mount and clamp plates, and the bolts are tightened sufficiently to ensure that, in the case of multiple-plate targets, the plate surfaces are in intimate contact. The experimental arrangement is as shown in Fig. 2 and as discussed above.

In Appendix A, Table 2A provides details of the experiments performed in this series (SST84SST143). Included are experiment number, a description of the target type, impact velocity, whether or not the projectile passed through the target, and residual penetration into the witness plate, if any. In Appendix B, Table 2B summarizes the experimental results by listing our estimate of the ballistic limit for each target. The ballistic limit is calculated by averaging the lowest recorded velocity at which the projectile passed through the target and the highest velocity at which it did not. The number following " \pm " in the table is half the difference between the two velocities.

Figure 11 graphs ballistic limit results for experiments in which the target consisted of a single plate. For reference we also include Pratt \& Whitney's "just contained" curve for 4-in. $\times 4$-in. titanium plates impacted by .30-caliber jacketed projectiles, as well as a datum for each of the 6061-T6 and 7039-T6 aluminum alloys. The diamond-shaped data points are results from LLNL's titanium experiments discussed in the previous section.

Table 2. Material properties.

\begin{tabular}{lccc}
\hline Material & Yield (ksi) & UTS (ksi) & \% elongation \\
\hline 6061-T6 Al & 40 & 45 & 12 \\
7039-T61 Al & 48 & 58 & 14 \\
$5182 \mathrm{Al}$ & 19 & 40 & 25 \\
7075-T6 Al & 73 & 83 & 11 \\
\hline 6Al-4V Ti & 135 & 145 & 15 \\
Grade 4 Ti & 85 & 103 & 22 \\
\hline 6090/SiC 25\% (no H.T.) & 38 & 51 & 4 \\
6090/SiC 25\% (T6 H.T.) & 61 & 74 & 3 \\
6090/SiC 25\%/ & & & \\
5182 laminate (no H.T.) & 23 & 39 & 17 \\
6090/SiC 25\%/ & & & 7 \\
5182 laminate (T6 H.T.) & 34 & 48 & \\
\hline
\end{tabular}




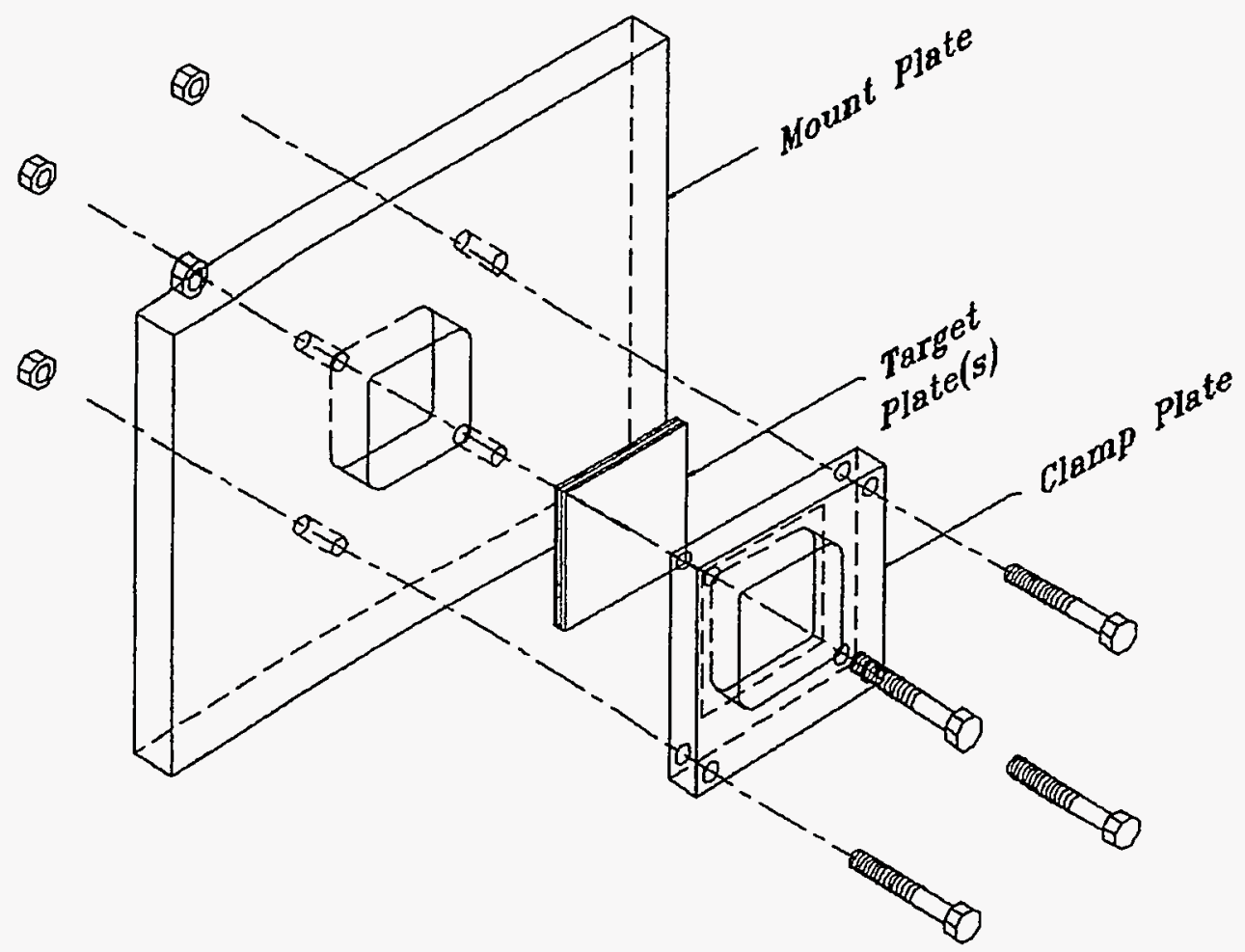

Figure 10. Details of the target mounting system.

Aluminum Alloys - Single Plate ( 3 1/4" x 3 1/4")

0.30 Caliber Copper Jacketed Steel Projectile*

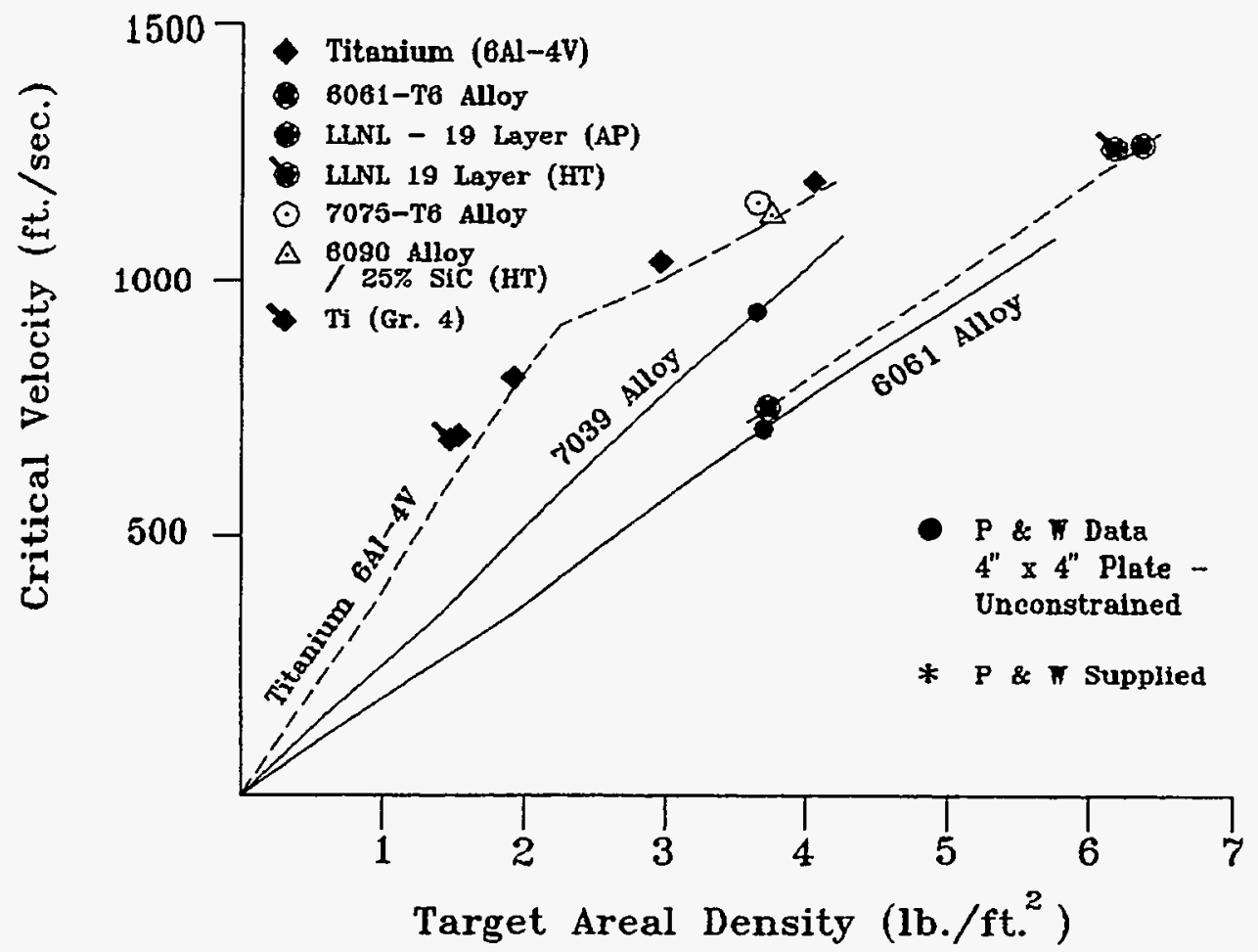

Figure 11. Single-plate ballistic limit data. (Pratt \& Whitney data included for reference.) 
From Fig. 11, we see that the critical projectile velocity for the 6061-T6 aluminum singleplate targets (circled square) agrees closely with the datum provided by Pratt $\&$ Whitney. Estimates of the critical velocities for the as-pressed and heat-treated LLNL 19-layer laminates (circled hexagon and circled hexagon with tail) indicate that the heat treatment had little effect on ballistic performance. If the assumption is made that the relationship between target areal density and critical velocity is essentially linear* over the velocity range shown, then the ballistic performance of the single-plate laminate is comparable to that of 6061-T6 aluminum. Figures 12 and 13 show the condition of the front and rear of postexperiment target SST-113. Material failure took place primarily in the plug mode. There is evidence of delamination and petaling near the projectile exit on the rear surface of the plate.

The LLNL 19-layer laminates consist of alternating plates of 6090 aluminum alloy discontinuously reinforced with $25 \%$ particles of silicon carbide $^{\dagger}$ and 5182 aluminum alloy. $¥$ Initially, the plates are cut into 2.0-in. squares and chemically descaled and degreased. Then, the laminates are mechanically assembled and hot-pressed in vacuum. The furnace atmosphere is evacuated and back-filled with argon gas. The furnace temperature is increased to $450^{\circ} \mathrm{C}$, and the laminate is reduced in thickness by hot-pressing from $2.1 \mathrm{in}$. to about $0.6 \mathrm{in}$. Then, the laminates are cooled, trimmed, and finally heat-treated to the T6 temper.

Both of the single plates of 7075-T6 aluminum alloy and $6090 \mathrm{DRA}$ (heat-treated) performed as well as the single-plate $\mathrm{Ti} 6 \mathrm{Al}-4 \mathrm{~V}$ alloy. The specific ultimate tensile strengths (ratio of strength to density) of the two aluminum alloys are comparable to that of the titanium alloy. However, the elongation to failure of the $6090 \mathrm{DRA}$ is much lower than either the 7075-T6 aluminum alloy or the 6Al$4 \mathrm{~V}$ titanium alloy.

\footnotetext{
* The assumption of a linear relationship between areal density and ballistic limit for aluminum alloys, laminates, and metal matrix composites has not been tested or verified by LLNL. The solid straight lines shown in Fig. 11 are duplicates of those appearing in graphical representations of data provided by Pratt \& Whitney.

t The $609025 \%$ DRA was purchased from Composite Specialties Inc. of Chatsworth, Calif.

$\ddagger$ The 5182 alloy aluminum was purchased from Kaiser Aluminum.
}

Figure 14 shows the rear surface of a single 6090 DRA after a ballistic event. Clearly, aluminum spall was ejected from the rear surface of the plate under the projectile during the ballistic event; evidence of the resulting spall ring around the projectile exit cavity is quite apparent. No other aluminum alloy evaluated exhibited rearsurface spall.

A single plate of commercially available (Grade 4) pure titanium plate also was evaluated. The Grade 4 titanium is not as strong and is more ductile than the 6Al-4V titanium alloy (see Table 2). However, as shown in Fig. 11, we saw little distinction between the performance of the pure and alloyed titanium single plates.

A single experiment (SST-118) was performed on a specially prepared laminate created at LLNL. This was a 19-layer, 0.445 -in.-thick laminate made* from layers of material in which a central rectangular region on the front and back of each plate was masked off during descaling. After the masks were removed, the plates were bonded in the usual manner. The result was a laminate bonded on the periphery, but with little or no bonding in the central region. The plate was impacted by a projectile traveling just under $1300 \mathrm{ft} / \mathrm{s}$. As Fig. 15 shows, the laminate was not perforated; the projectile was trapped within its layers. Ballistic performance for this target was greater than that of completely bonded LLNL 19layer laminates of equivalent thickness, although precisely how much greater its performance is will not be known until further experiments are conducted.

Figure 16 graphs the data for experiments with three stacked plates. As before, Pratt \& Whitney data for single-plate $6 \mathrm{Al}-4 \mathrm{~V}$ titanium alloy and the 6061-T6 and 7039-T6 aluminum alloys are included for reference.

Although the total areal density for the triple-plate target of 6061-T6 aluminum is the same as for that of the single-plate 6061-T6 aluminum, ballistic performance is substantially improved (better than $200 \mathrm{ft} / \mathrm{s}$ greater) over that of the single plate. Performance is essentially equal to that of the single plate of 7039 aluminum alloy tested by Pratt \& Whitney. Disassembly of target SST-90 after ballistic testing shows succes-

\footnotetext{
* Members of the LLNL Manufacturing and Materials Engineering Division, Material Technology Group, have filed for a patent detailing the unique fabrication of the laminate and its applicability to turbine engine blade containment technology.
} 


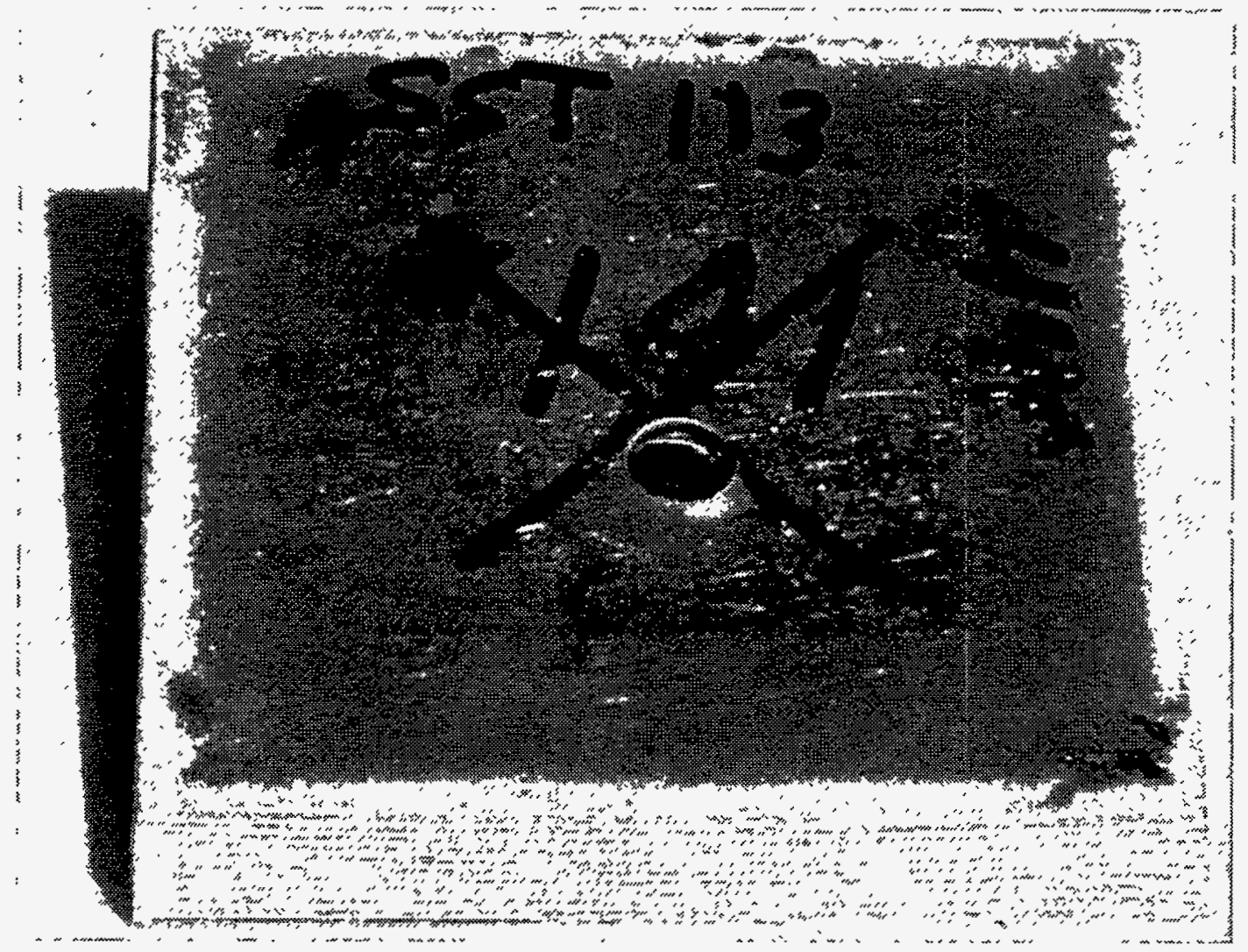

Figure 12. Front surface of a perforated 19-layer laminate consisting of alternate layers of 5182 aluminum and DRA.

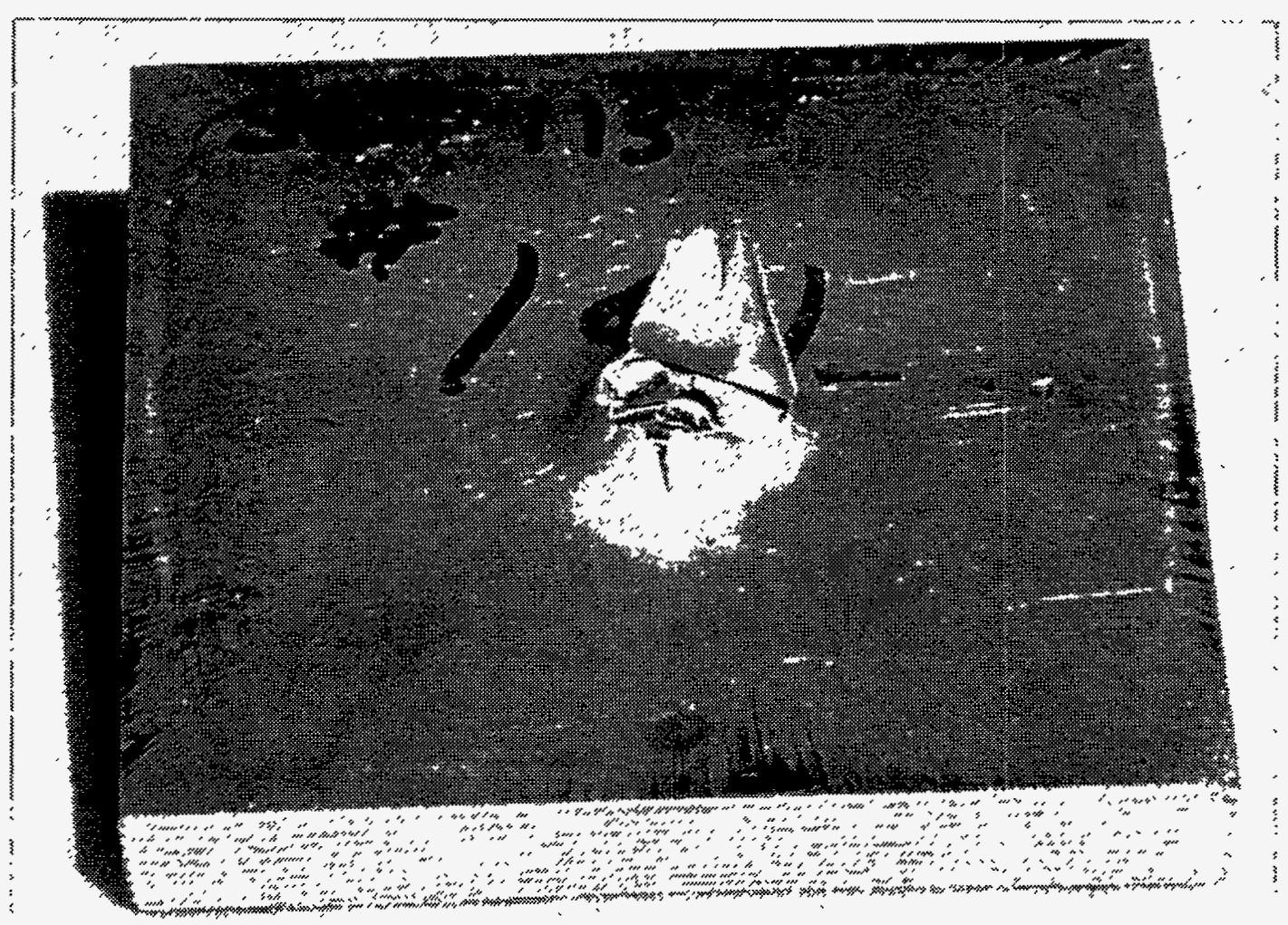

Figure 13. Rear surface of the 19-layer laminate shown in Fig. 12. Note the delamination and petaling near the rear surface. 


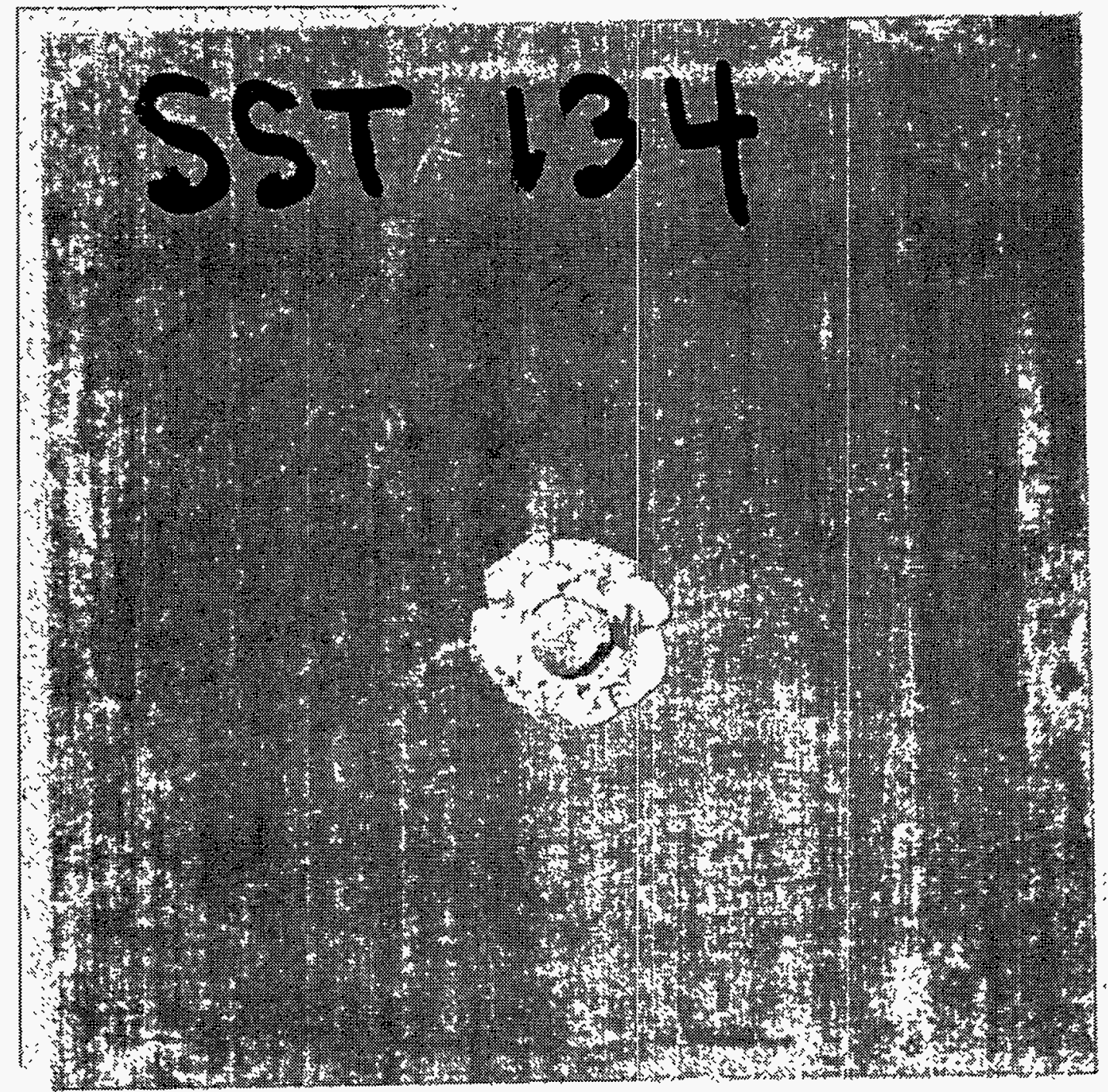

Figure 14. Rear surface of a DRA single plate. A substantial spall ring is quite apparent.

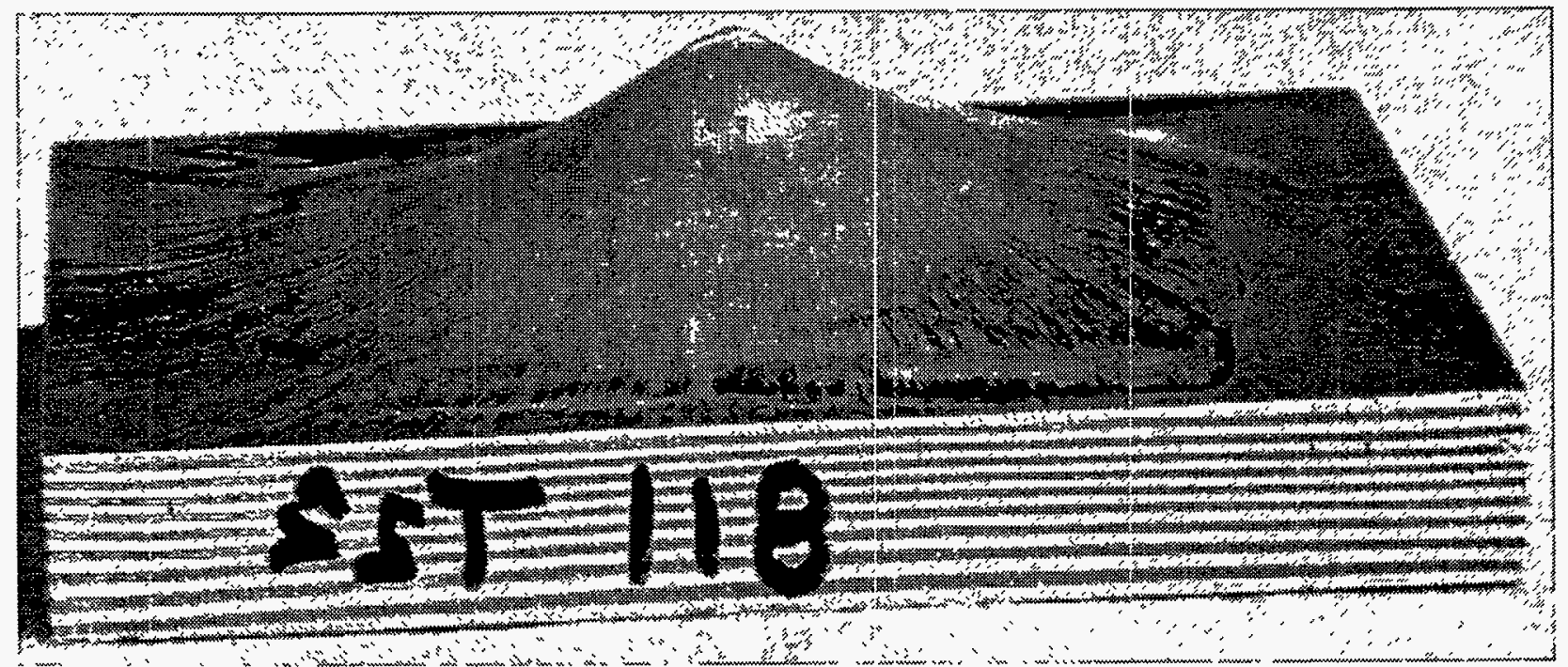

Figure 15, A specially prepared 19-layer laminate. The central region of the sample is unbonded between layers. A projectile is trapped inside the target. 


\section{Aluminum Alloys - Triple Plate (3 1/4" x $31 / 4^{\prime \prime}$ )}

\subsection{Caliber Copper Jacketed Steel Projectile*}

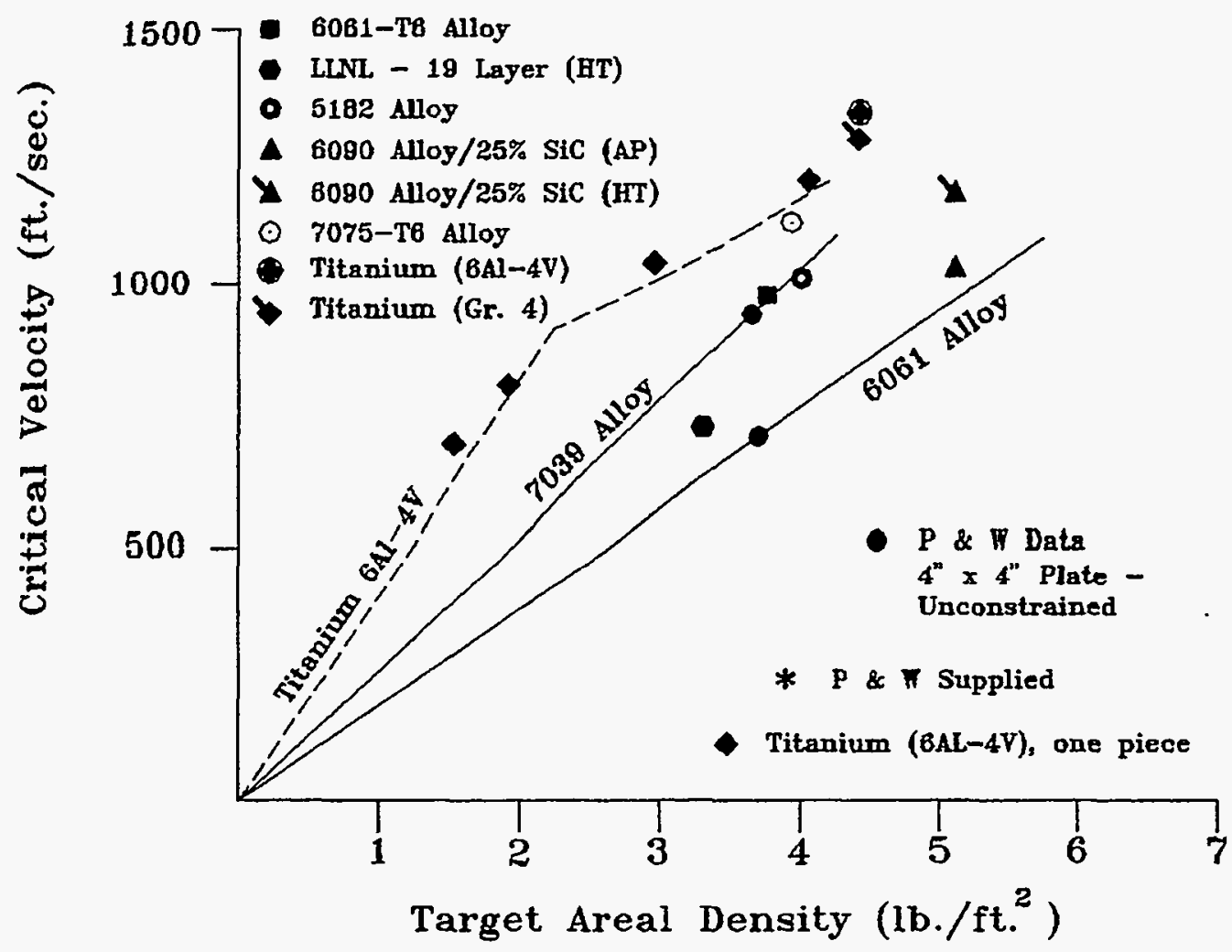

Figure 16. Plotted triple-plate ballistic limit data. (Pratt \& Whitney data included for reference.)

sive (front-to-back) plates to have undergone progressively more stretching and deformation. The back plate shows the most "coning," with slight cracking directly adjacent to the hole.

The performance of the triple plate of 7075T6 aluminum alloy (open circle) is quite interesting in that it is slightly inferior to that of its single-plate counterpart. Evidently, in laminate form, the inherent brittleness of the aluminum alloy prevents ductile tensile yielding in the successive plates of the laminate. As shown in Fig. 17, large fractures radiate from the impact location (projectile cavity in the target) on each plate of the laminate. Fracturing of the first plate is most limited; fracturing of the third is extensive. The heat-treated triple plates of the 6090 DRA after ballistic impact appear qualitatively similar to the 7075-T6 plates.

Performance of the LLNL 19-layer laminate plates (hexagonal data point) falls between that of the single-plate 6061-T6 aluminum target and that of the single-plate 7039-T6 aluminum target. These laminate targets (see Fig. 18), show pro- gressively greater plate deformation in successive plates, front to back. In all experiments in this set, the first plate to be impacted failed in a plugging mode, and the second also plugged, but with more peripheral plate distortion. When perforation of the target occurred, the third plate failed in a petaling mode.

Ballistic performance of the triple-plate 5182 aluminum target (doughnut-shaped data point) was equal to that of the triple-plate 6061-T6 aluminum target. Figure 19 shows that, near perforation, the 5182 aluminum alloy target underwent significant stretching prior to failure. Comparison of properties (see Table 2) reveals that 5182 alloy exhibits considerably higher elongation, considerably lower yield strength, and significant strain hardening.

Data from the $6090 \mathrm{DRA}$ plates with $25 \%$ $\mathrm{SiC}$ particles are represented on the graph as triangles. The triangle with a tail represents a datum from heat-treated triple-plate targets. The triangle without a tail represents a datum derived from targets tested in the as-received condition. 

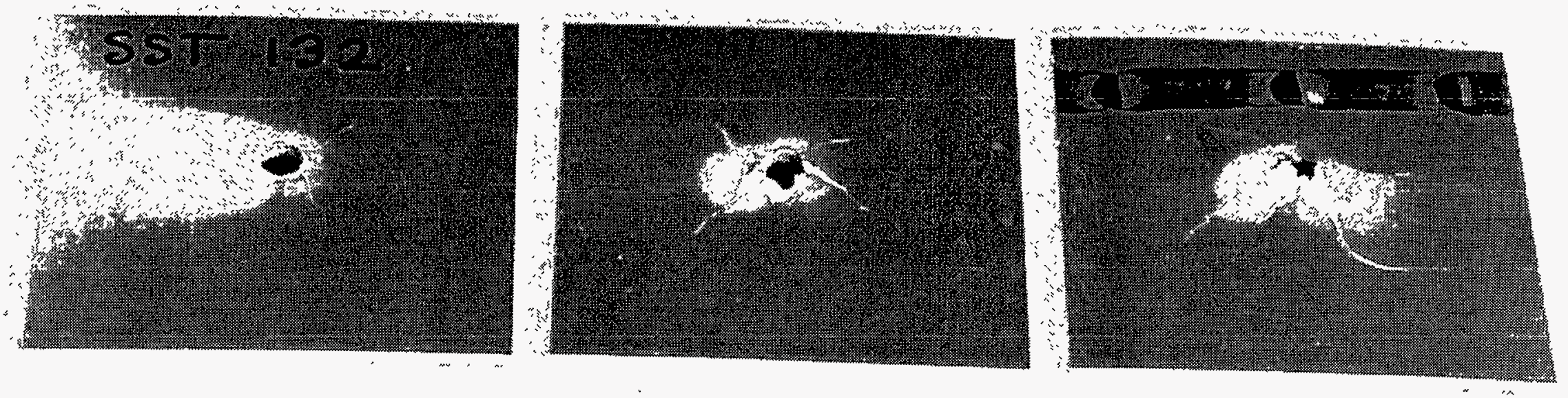

Figure 17. Rear surface of the three 7075-T6 aluminum alloy plates from a perforated triple target. Note the fracturing, particularly in the third plate.
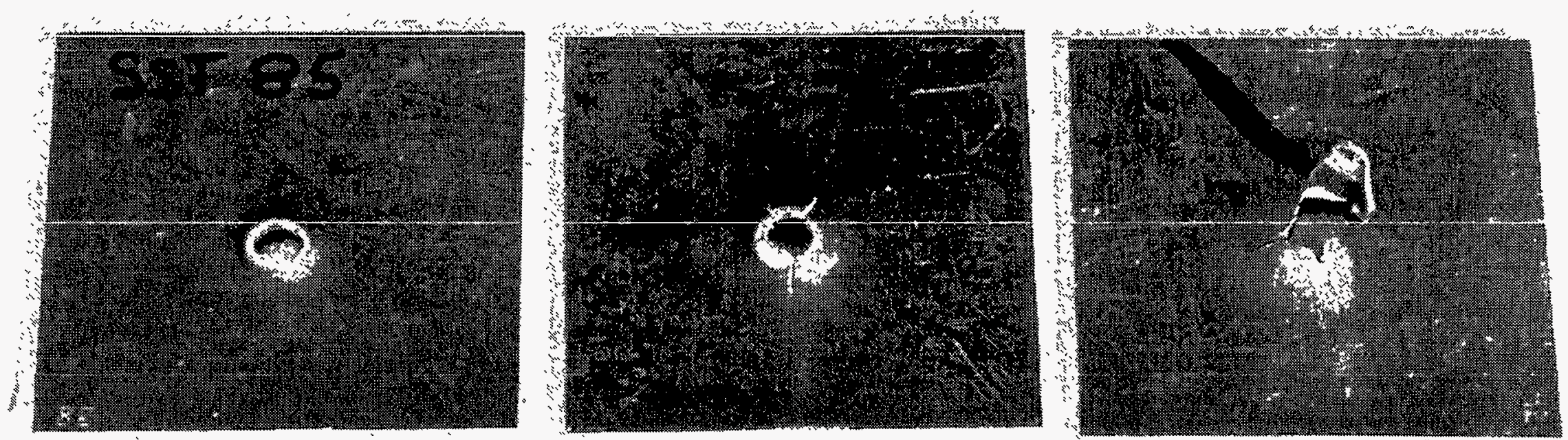

Figure 18. Rear surfaces of the three LLNL 19-layer laminate plates in a perforated triple-plate laminate target. The third plate failed by petaling. 


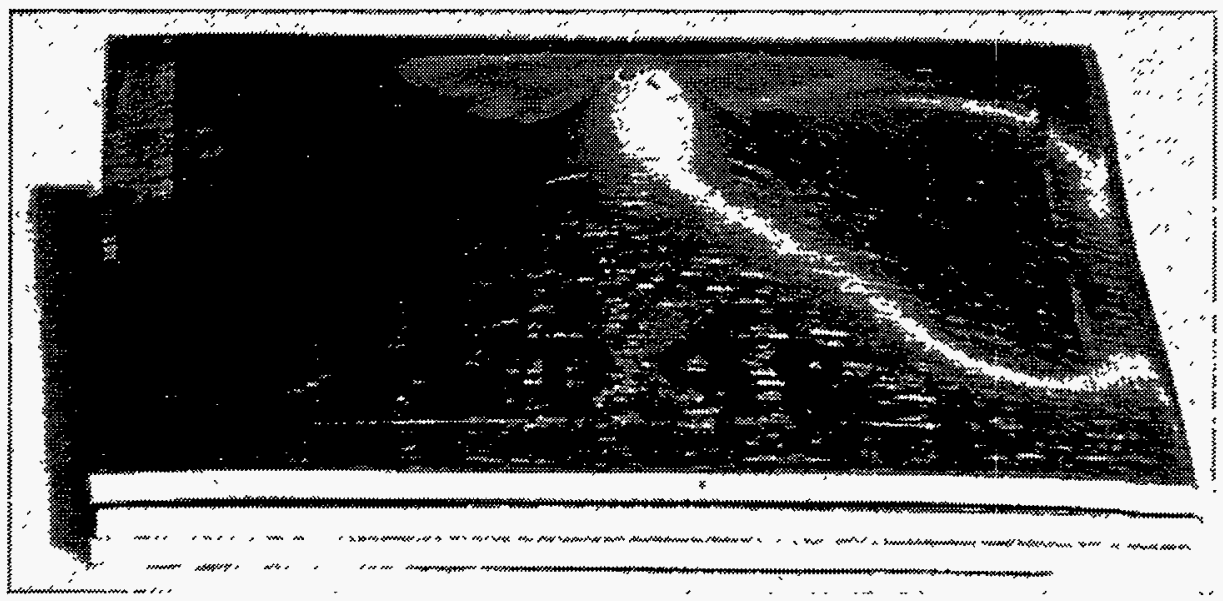

Figure 19. A triple-plate $\mathbf{5 1 8 2}$ aluminum target that was nearly perforated. Note the extensive stretching.

On the basis of an assumed linear relationship between areal density and ballistic limit, performance of both appears to fall between that of 6061-T6 $\mathrm{Al}$ and $7039 \mathrm{Al}$, although we have no data on the reference aluminum in the velocity range at which these experiments were conducted. The heat-treated plates outperform their as-received counterparts by about $150 \mathrm{ft} / \mathrm{s}$. However, although the critical projectile velocity against the 6090 DRA triple plate is comparable to that of the 7075-T6 triple plate, the areal density of the $6090 \mathrm{DRA}$ target is about $25 \%$ higher.

Figure 20 shows the rear surface of the "asreceived" target near perforation. Some periph- eral plate distortion is visible, although less than is seen with the aluminum alloys. Also, there is significant fracturing. Figure 21 shows the rear surfaces of two heat-treated, triple-plate targets. The left target has been impacted by a projectile traveling at a speed just below the ballistic limit. The target at the right has been impacted by a projectile traveling at a speed just above the ballistic limit. Both targets show some "coning," although there is less present than in as-received targets. Cracking is more extensive than in asreceived targets. As shown in Table 2, the strength of the $6090 / \mathrm{SiC} 25 \%$ aluminum, particularly when heat-treated, is relatively high, but its

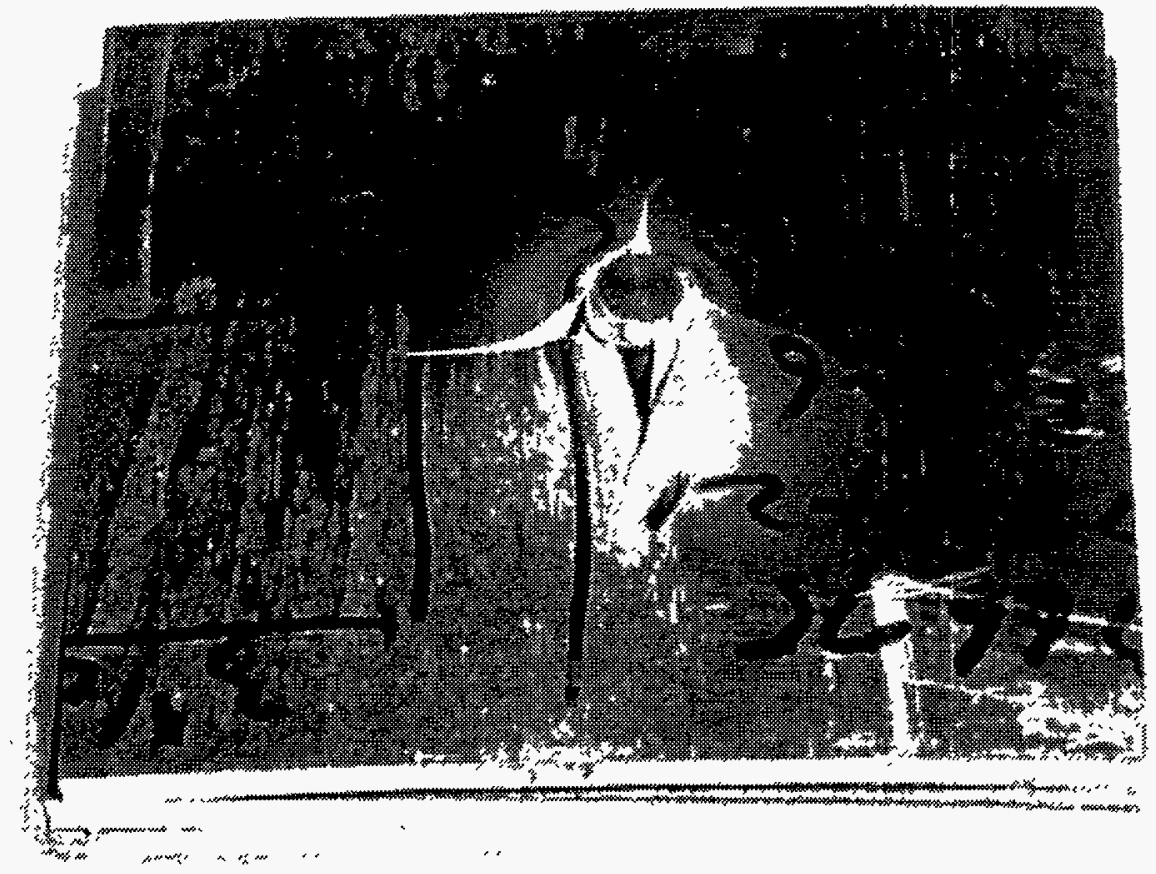

Figure 20. Projectile trapped in a 6090 DRA triple-plate target (not heat-treated). 


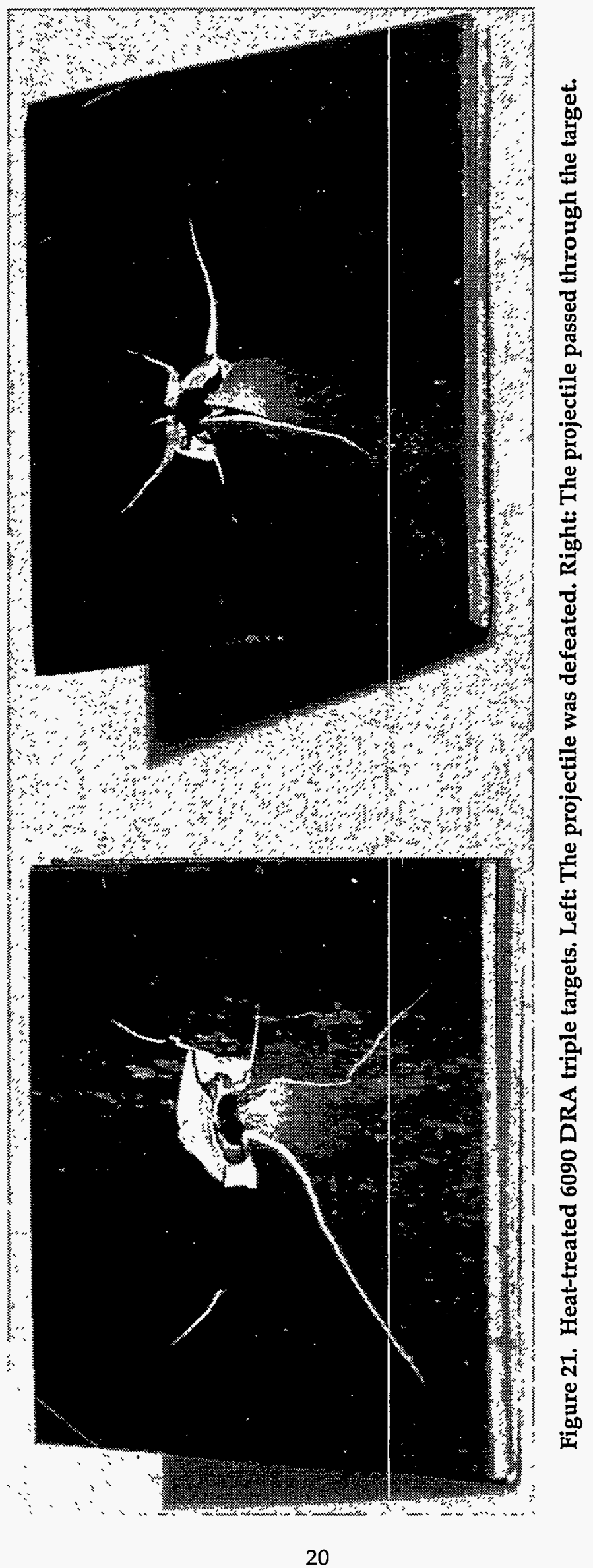


elongation to failure is only 3 to $4 \%$ (i.e., it is relatively brittle).

The ballistic performance of the Grade 4 pure titanium and the $6 \mathrm{Al}-4 \mathrm{~V}$ titanium alloy triple plates is better than that of $\mathrm{Ti} 6 \mathrm{Al}-4 \mathrm{~V}$ single plate. Of the two materials, the Ti $6 \mathrm{Al}-4 \mathrm{~V}$ triple plate produced the higher projectile critical velocity and had slightly more pronounced local deformation about the projectile crater in the target. However, the extent of the titanium deformation, although qualitatively similar to that observed in the 6061-T6 and 5182 aluminum alloy triple plates, is significantly less pronounced. We observe plugging with little local deformation in the first titanium plate, progressing to plugging with modest local deformation in the third plate.

It appears that the distinction between superior single- or multi-plate ballistic performance may be driven by the trade-off of inherent strength (tensile) and ductility of the materials under evaluation. Two extremes exist-one of high tensile (and shear) strength with little ductility. (elongation to failure) - the other of low tensile strength with large ductility. The former may perform better as a single plate; the latter may perform better in multi-plates.

Creating laminates of alternating layers of the two extremes seems to inhibit the effectiveness of each. Ordering them so that the highstrength material precedes the more ductile material may provide a better solution. One does not want succeeding plates of a laminate to fail prematurely through fracture or spalling. The efficiency and effectiveness of a light ceramic armor is based on an analogous perspective-a very high-compressive-strength (very lowtensile-strength) material supported by a stiff, more ductile material (metal or organic).

\section{Ballistic Experiments and Geometric Scaling}

In this series of ballistic experiments, we examined underlying issues related to the concept of geometric scaling by means of identical terminal ballistic experiments at two geometric scales. We found that geometric scaling is valid when the target failure mode is independent of scale and is not valid when the target failure mode changes with scale. Over the range of impact speeds tested, the projectiles behaved, essentially, as rigid bodies while penetrating the targets. Only at the highest impact speeds was modest projectile deformation observed.

The experimental plan consisted of two primary groups of terminal ballistic experiments. In the first set of experiments, we launched rightcircular-cylindrical projectiles from our .30caliber gun at titanium plates of fixed lateral dimension and two nominal thicknesses. In the second set of experiments, we launched rightcircular-cylindrical projectiles from our .50caliber gun at titanium plates. The target plate lateral dimensions and thicknesses for the second set of experiments were $5 / 3$ of the lateral dimensions and thicknesses of the target plates in the first set of experiments. For each combination of projectile and target, we performed enough experiments to estimate the projectile ballistic limit speed. Targets were always oriented normal to the flight path of attacking projectiles.

Figure 22 illustrates the projectiles and targets used at the two scales. "Baseline Scale $(1 / 1)^{\prime \prime}$ refers to the first group of experiments based on projectiles launched from our .30-caliber gun. "5/3 Scale" refers to the second group of experiments based on projectiles launched from our .50-caliber gun. The projectiles were made either from tool steel hardened to a uniform Rockwell-c38 or from $6 \mathrm{Al}-4 \mathrm{~V}$ titanium alloy rod stock. The $6 \mathrm{Al}-4 \mathrm{~V}$ titanium alloy projectiles and target plates were fully annealed (Rockwell-c34) at LLNL. We performed independent hardness tests after heat treatment to ensure uniformity and satisfaction of the hardness specifications.

The original experimental plan consisted of eight sets (projectile/target combinations) of experiments; i.e., two projectiles vs two target plate thicknesses at two geometric scales. Early in the experimental program, we found that the impact speed of the titanium projectiles needed to perforate the thicker target plates was above $2000 \mathrm{ft} / \mathrm{s}$. Since a projectile speed of $2000 \mathrm{ft} / \mathrm{s}$ is significantly above the range of speeds of interest for turbine blade containment, we omitted these two sets from further experiment.

The experimental setup was again as illustrated in Fig. 2. Smooth-bore guns were used in all the experiments.* Projectiles were launched within a simple, one-piece, polypropylene sabot,

\footnotetext{
* A 14.5-mm smooth-bore gun was used to launch several of the 5/3-scale projectiles to higher speeds. This was necessary because the relatively thin wall of the .50 -caliber sabot collapsed during launch from the .50-caliber gun at corresponding projectile speeds.
} 
Baseline Scale $(1 / 1)$

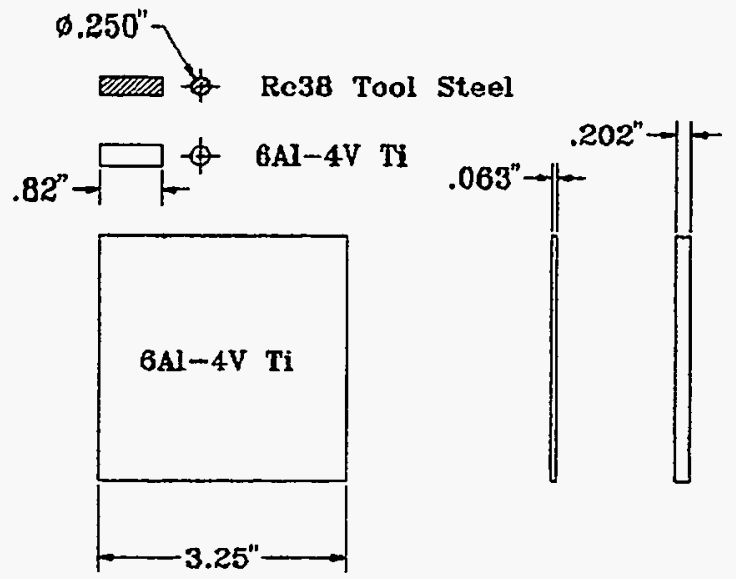

$5 / 3$ Scale

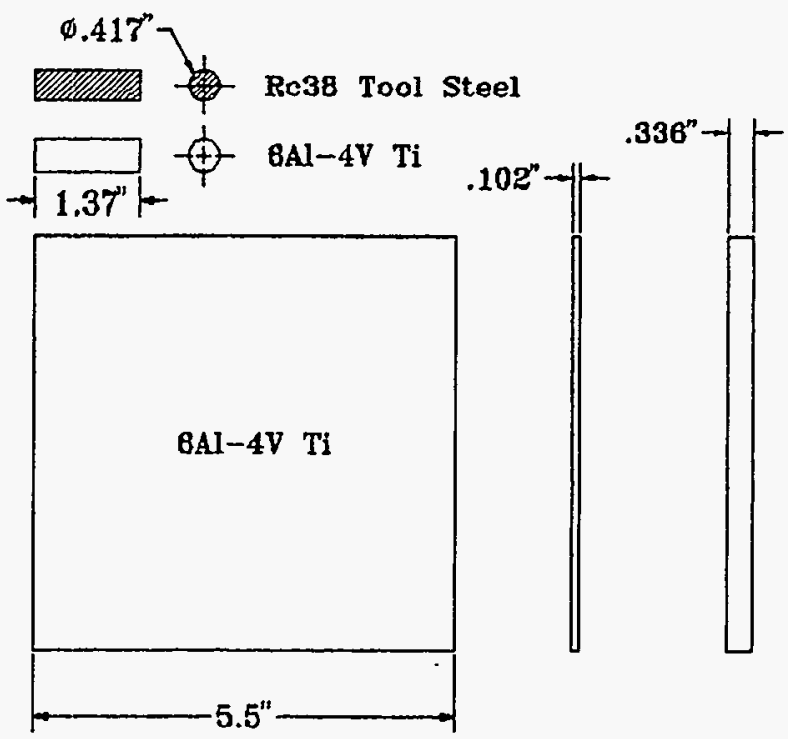

Figure 22. Projectiles and targets used in the scaling experiments.

as shown in Fig. 23. A foil switch served to initiate the timing sequence for the $150-\mathrm{kV} x$ rays, which fire in succession with preset delays. The two $x$ rays provide an accurate measure of projectile velocity and allow us to monitor the state of a projectile, particularly just before target impact. A second foil switch was used so that we could make a redundant estimate of projectile velocity.

Examination of some of the radiographs showed that the plastic sabots were stripped from the projectiles as they passed through the first foil switch and so did not affect projectile penetration of a target. For some of the .50 -caliber gun experiments, which required higher projectile muzzle speeds, a thin aluminum sheet was placed in front of the first foil switch to prevent pre-triggering the switch.

Figure 10 is a drawing of the target mounting system used during the experiments. Two target mounting systems were fabricated from the same materials. One system was used for the .30-caliber projectile experiments; the other, a 5/3-scale replica of the first, was used for the .50caliber projectile experiments. The clamp plate and bolts were made of mild steel; the mount plate was made from 6061-T6 aluminum alloy. When a target was being mounted, the bolts were finger-tightened only so that the target perimeters were supported but not fully constrained.
In Appendix A, Table A3 is a summary of the .30 caliber projectile (baseline) experimental data (SST-53 through SST-67). Recorded are each projectile/target thickness combination, experiment number, projectile impact speed, perforation satisfaction, residual penetration into a 6061T6 aluminum alloy witness plate, projectile pitch in the vertical plane just prior to target impact, and pertinent comments. Projectile pitch was not specifically measured if it was less than $0.5^{\circ}$. In Appendix A, Table A4 is a summary of the .50 caliber projectile (5/3-scale) experimental data in the same format.

In Appendix B, Table B3 contains our estimates of the projectile critical speeds for each projectile/target set. "Limit Speed" is determined by calculating the arithmetic average of the lowest projectile speed at which a projectile perforated a target and the highest projectile speed at which a projectile did not perforate a target. The number following the " \pm " is one-half the difference between the two speeds. "Biased Limit Speed" is determined from the experimental data and is an adjusted limit speed based on our examination of the pitch of the projectiles and the residual (witness plate) penetrations observed for a particular experimental set. We judge a biased limit speed, when one is presented, to be more representative of the true projectile limit speed for that particular projectile/target combi- 


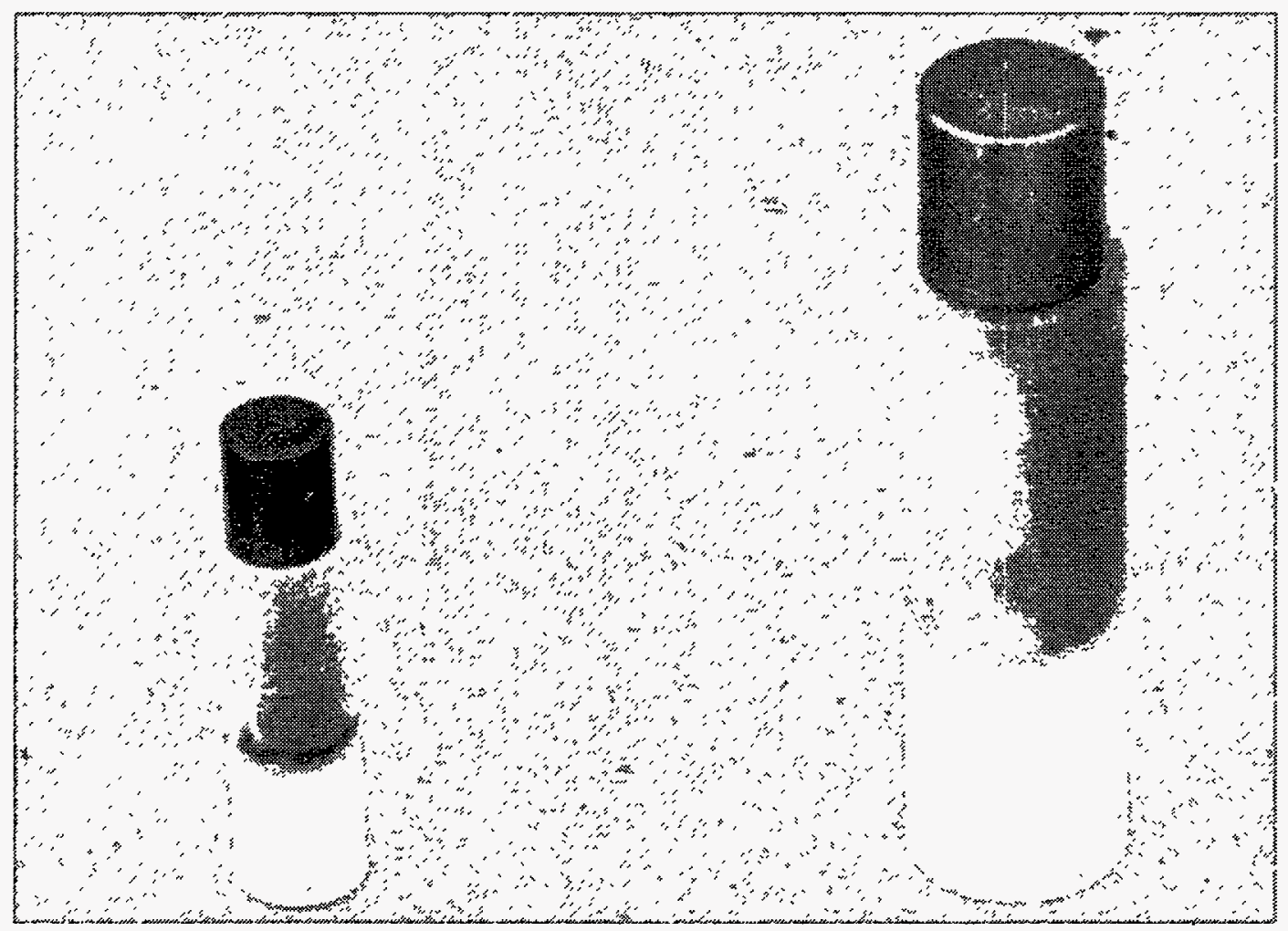

Figure 23. Projectiles in sabots. Left: Baseline-scale tool steel (Rockwell-c38). Right: 5/3scale $6 \mathrm{Al}-4 \mathrm{~V}$ titanium alloy.

nation. The target failure mode at projectile speeds near the ballistic limit speed is also recorded.

Examination of the target plates after the experiments revealed that, near the projectile ballistic limit speeds, the baseline-scale thinner target plates failed in the petal mode when the plates were impacted by steel and by titanium projectiles. Figure 24 shows the front (impact) faces of two target plates (left plate impacted by a steel projectile, right plate impacted by a titanium projectile) that failed in the petal mode and also shows the corresponding recovered projectiles.

At $5 / 3$ scale, the corresponding thinner targets impacted by steel projectiles failed in the shear (plugging) mode. Figure 25 shows the front faces of two titanium plates struck by steel projectiles. The left target plate was impacted by a projectile at a speed below its limit speed; the right target plate was impacted by a projectile at a speed above its limit speed. The recovered steel projectiles are placed beneath the target plates in the photograph. When the plates were impacted by titanium projectiles, we found that, near the projectile limit speeds, the plates failed either in the shear mode or in a "mixed" (transition) mode. As shown in Fig. 26, a mixed failure is primarily a shear failure with evidence that some tearing of the target plate adjacent to the perforation occurred. The front face of the target plate is shown in the photograph.

At baseline and $5 / 3$ scales, the thicker target plates, impacted by steel projectiles, failed in the shear mode. Figure 27 shows the front faces of target plates and the recovered projectiles at both scales below and above the projectile limit speed. The similarity between the corresponding states of projectiles and targets at the two scales is apparent. When the target slightly overmatched the projectile, the recovered projectile flared (plastically deformed) at the impact end; when the projectile slightly overmatched the target, the flared region of the projectile was sheared away as the projectile penetrated through the target.

For many of the sets contained within the two primary groups of experiments defined in our plan, we observed that the target failure mode was shear-plug failure. Appendix $C$ describes a simple analytic model for the shear failure of thin metallic plates impacted by blunt projectiles that remain rigid during perforation of 


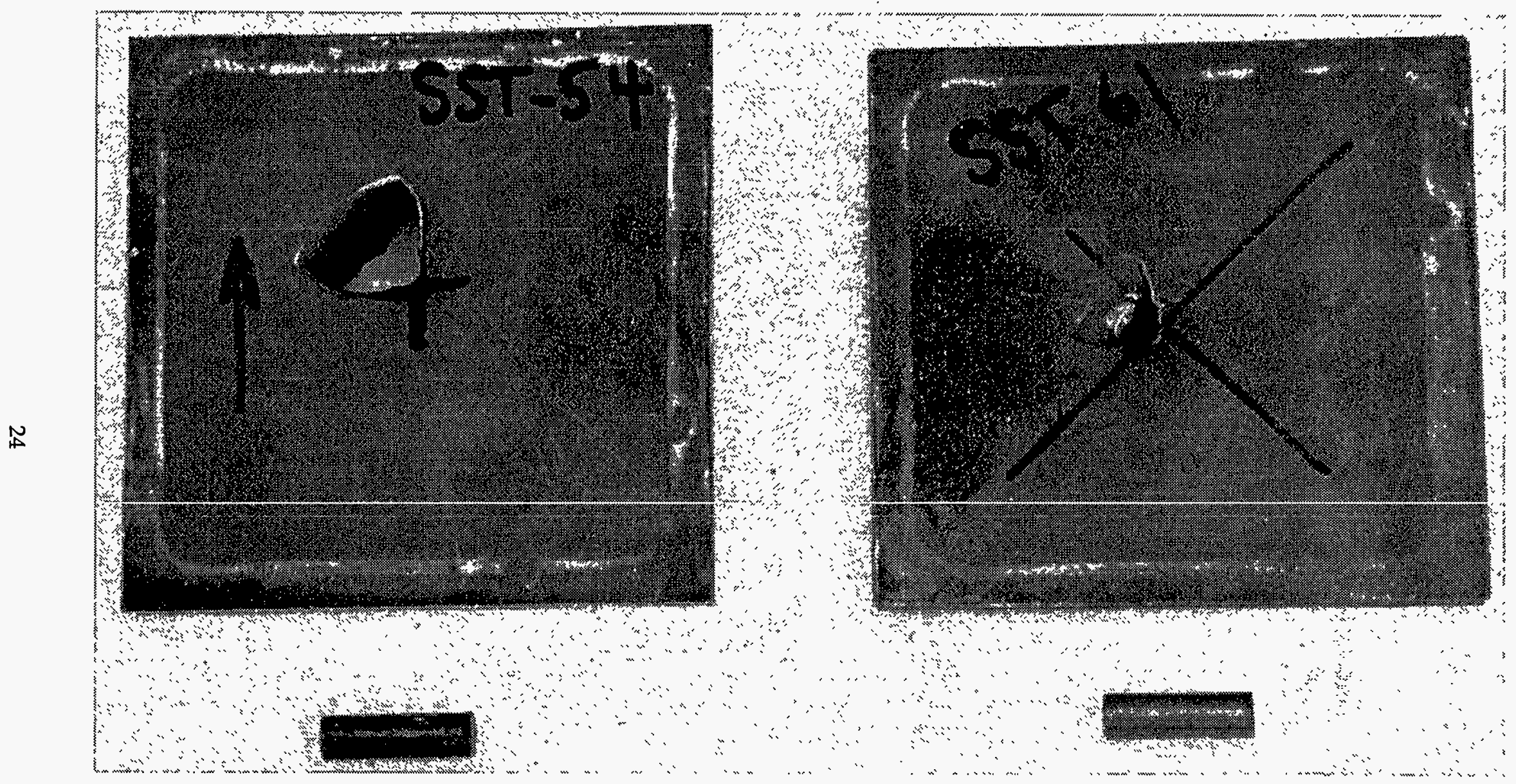

Figure 24. Baseline-scale plates that failed by petaling. The targets were impacted by the projectiles below them: steel (left) and titanium (right). 


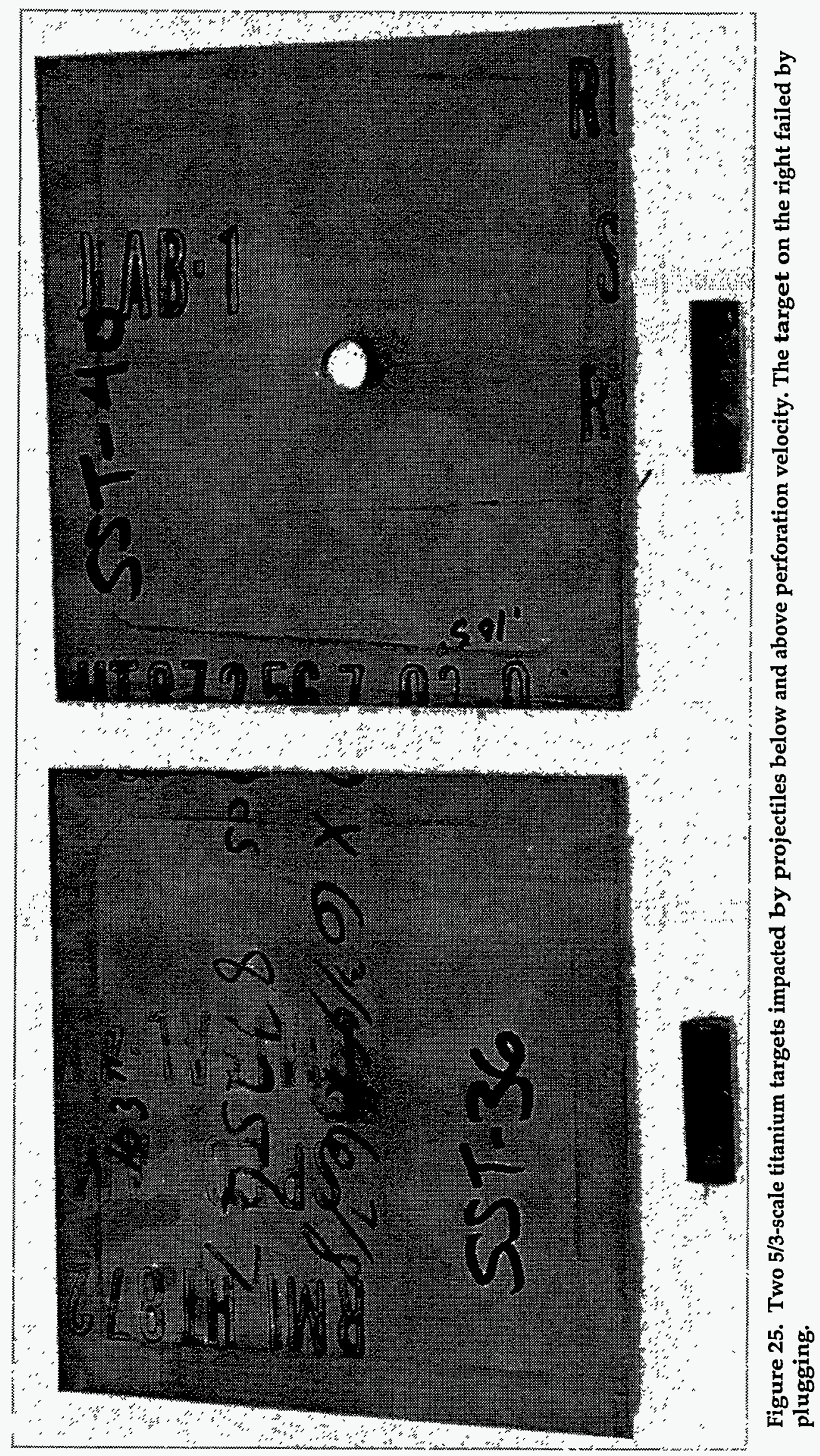




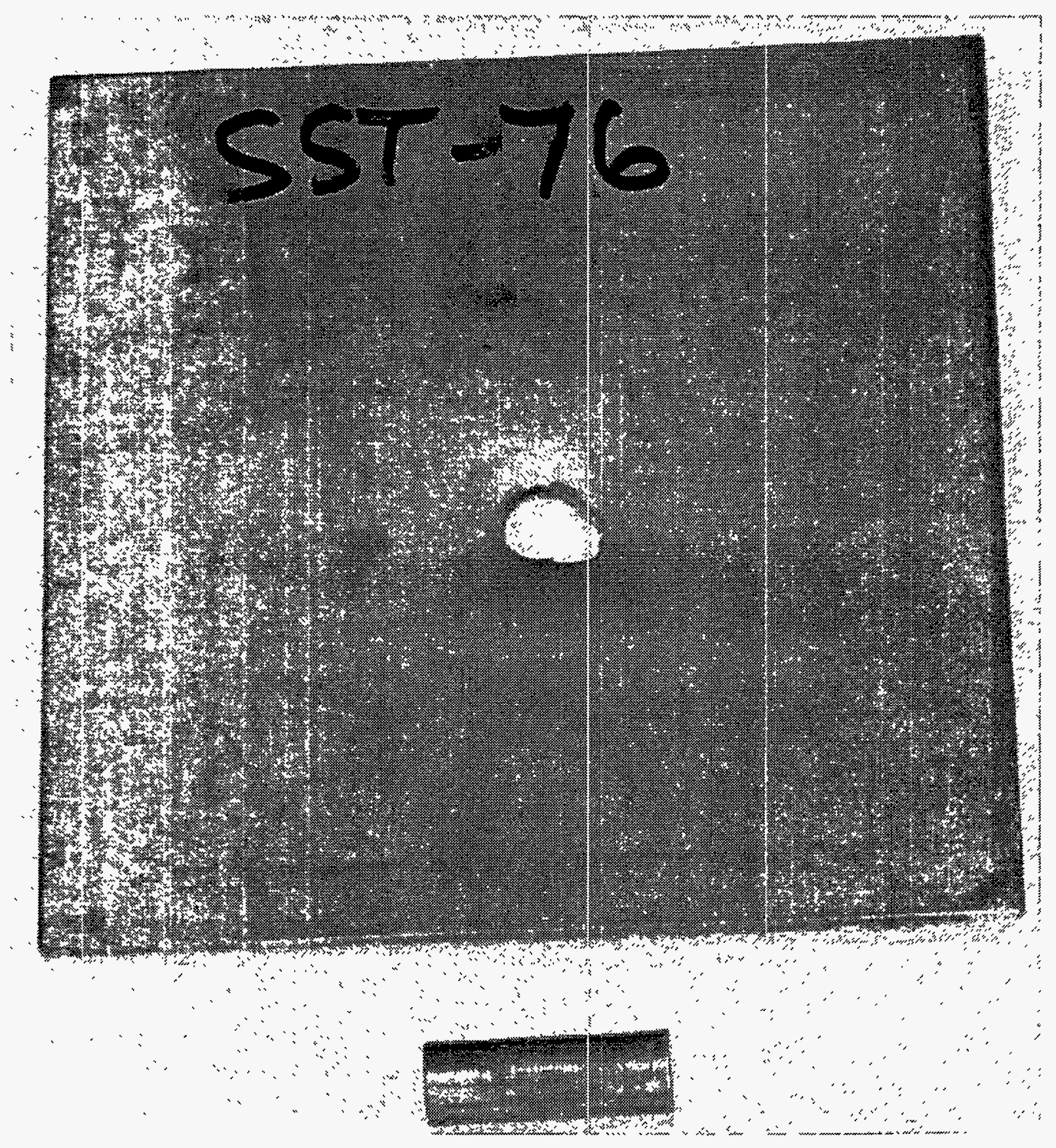

Figure 26. Example of a "mixed mode" failure. 

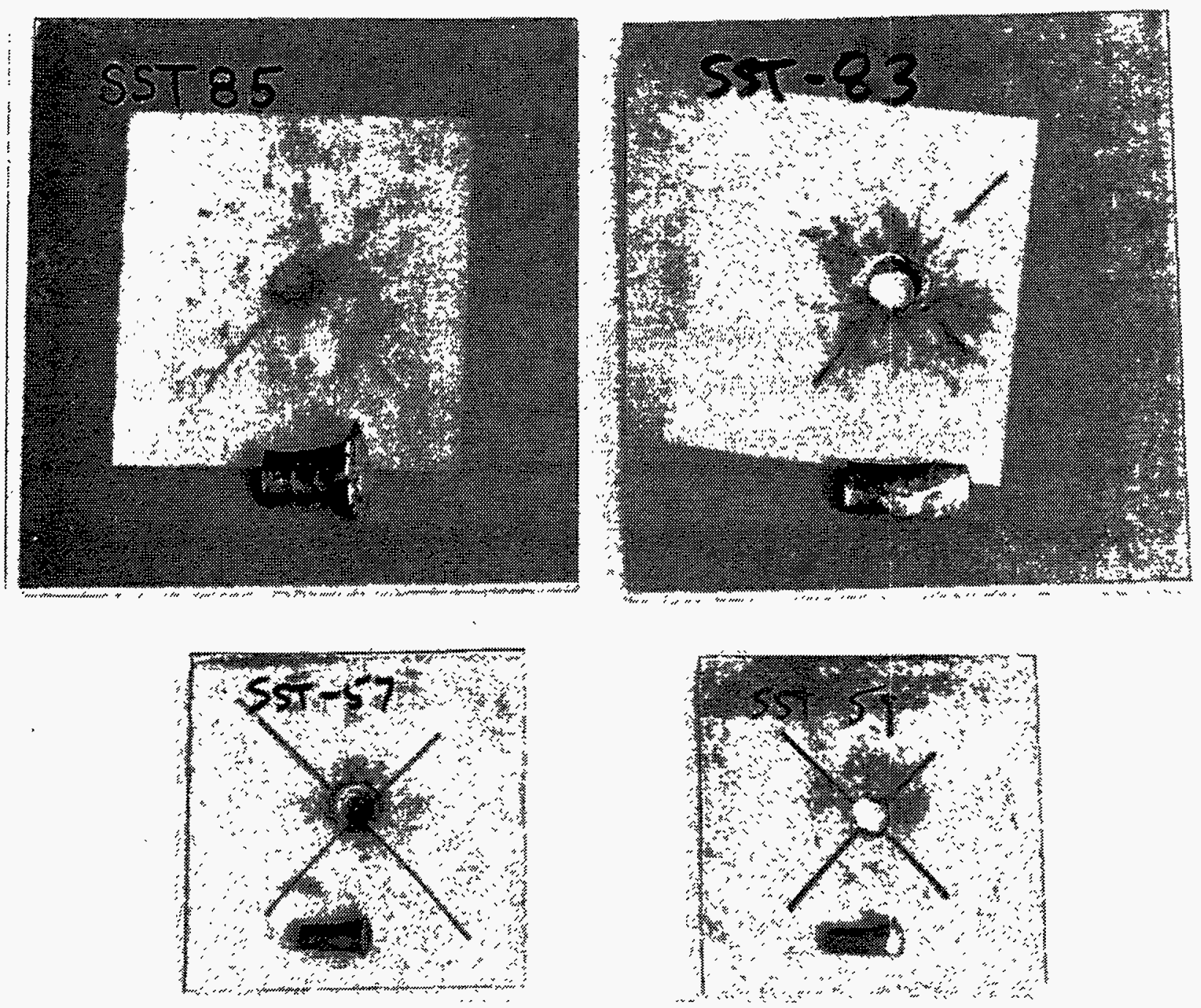

Figure 27. Examples of impacts on relatively thick titanium targets at $5 / 3$ scale (top) and baseline scale (bottom) at above and below perforation velocity. Note the similarity in projectiles and targets at the two different scales. 
a target. The first result taken from this model that we will use is as follows:

Changing projectile material to a material of higher density - e.g., from titanium to steel-correspondingly lowers the limit speed against the same target by the square root of the ratio of the projectile densities. The geometry of the projectile is fixed and independent of the choice of material.

Our analysis of the experimental data began by examining the outcomes of the experimental sets in which steel and titanium projectiles fired from a .30-caliber gun impacted, at normal incidence, 3.25 -in. square titanium plates $0.62 \mathrm{in}$. thick. Figure 28 shows the limit speeds for .30caliber copper-jacketed steel (6.8-g) projectiles against 3.25-in. square Ti $6 \mathrm{Al}-4 \mathrm{~V}$ alloy plates as a function of target areal density (data provided by Pratt \& Whitney). Our experiments were similar to and consistent with those performed by Pratt
\& Whitney, but instead of copper-jacketed projectiles, we used tool steel and Ti $6 \mathrm{Al}-4 \mathrm{~V}$ alloy projectiles in a right-circular-cylindrical geometry. For our experiments using the .30caliber gun, the dimensions of our projectiles correspond identically to those of the hard-steel cores contained within the copper-jacketed steel projectiles.

The open symbols in Fig. 28 represent the estimated limit speeds of the steel and titanium projectiles. These limit speeds are above Pratt \& Whitney data for the same target areal density. However, the mass of our steel and titanium projectiles are 5.2 and $2.95 \mathrm{~g}$, respectively. We now use the first result from our shear-plugfailure model: if we assume that our projectiles had a mass of $6.8 \mathrm{~g}$ (i.e., assume a density so that the resulting mass is $6.8 \mathrm{~g}$ ), then the corresponding limit speeds of the projectiles move vertically downward on Fig. 28. The closed symbols shown on Fig. 28 are the result of this adjustment. Now, projectiles of the same mass and geometry can be compared directly. We further observe that the

\section{.30 Caliber Projectiles, Titanium Targets}

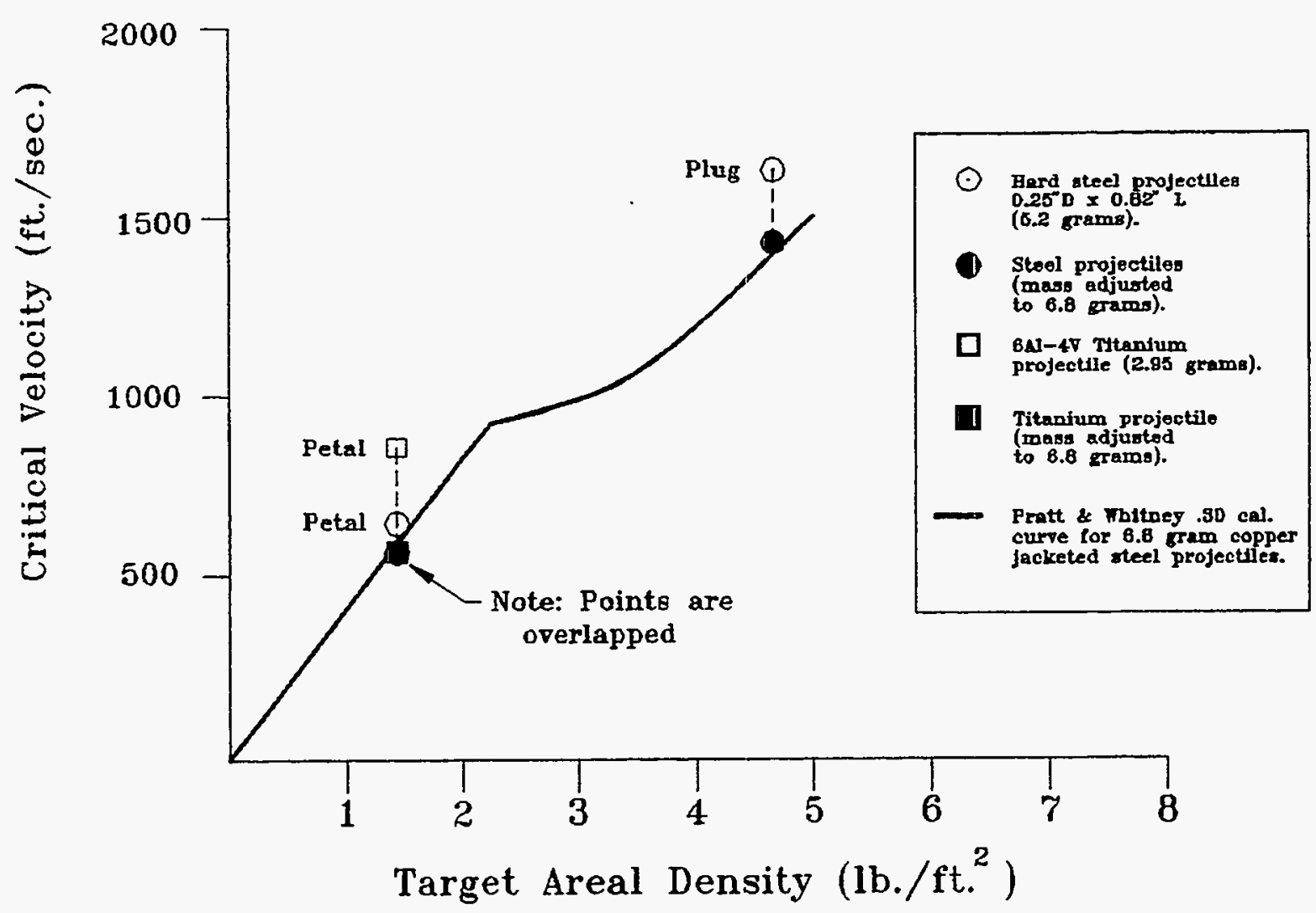

Figure 28. Data for 0.25-in.-diameter steel and titanium projectiles impacting 6Al-4V titanium plates. The dotted lines indicate adjustment for projectile mass. 
target failure modes found in our experiments are the same as found by Pratt \& Whitney-shear failure at the higher target areal density and petal failure at the lower target areal density. We find that the projectile limit speeds derived from our experiments agree quite well with the Pratt \& Whitney data.

Figure 29 shows the Pratt \& Whitney data (.30 caliber) again for the limit speeds of .30 caliber copper-jacketed steel (6.8-g) projectiles against 3.25-in. square $\mathrm{Ti}$ 6Al-4V plates as a function of target areal density. Also shown is the same LLNL experimental data as in Fig. 28. To the right of the .30-caliber Pratt \& Whitney data is the assumed "perfectly scaled" .50-caliber relationship between projectile limit speed and target areal density. Perfect geometric scaling means that, if we increase projectile size by a factor of $5 / 3$ (while maintaining the properties of the projectile material), we expect that the thickness of the metallic target plate (again while maintaining the properties of the target plate material) must be increased by the same factor of $5 / 3$ so that the limit speed of the larger projectile remains the same as that of the smaller projectile. In addition, perfect geometric scaling inherently assumes that (a) the target plates at both scales are mounted in a geometrically similar manner using the same materials for the mounting system and (b) the failure mode of the target plates is the same near the limit speed for projectiles of correspondingly different geometric sizes. We calculate that a .50-caliber, copper-jacketed, steelcored projectile has a mass of $31.5 \mathrm{~g}\left[6.8 \times(5 / 3)^{3}\right]$.

We used tool steel and $\mathrm{Ti} 6 \mathrm{Al}-4 \mathrm{~V}$ projectiles in a right-circular-cylindrical geometry for our experiments using the .50 -caliber gun. They are geometrically similar to and a factor of $5 / 3$ larger than the projectiles fired from the .30-caliber gun. The open symbols in Fig. 29 adjacent to the ".50 Caliber" relationship display the estimated limit speeds of the steel and titanium projectiles. The

\section{.30 \& .50 Cal. Projectiles, Titanium Targets}

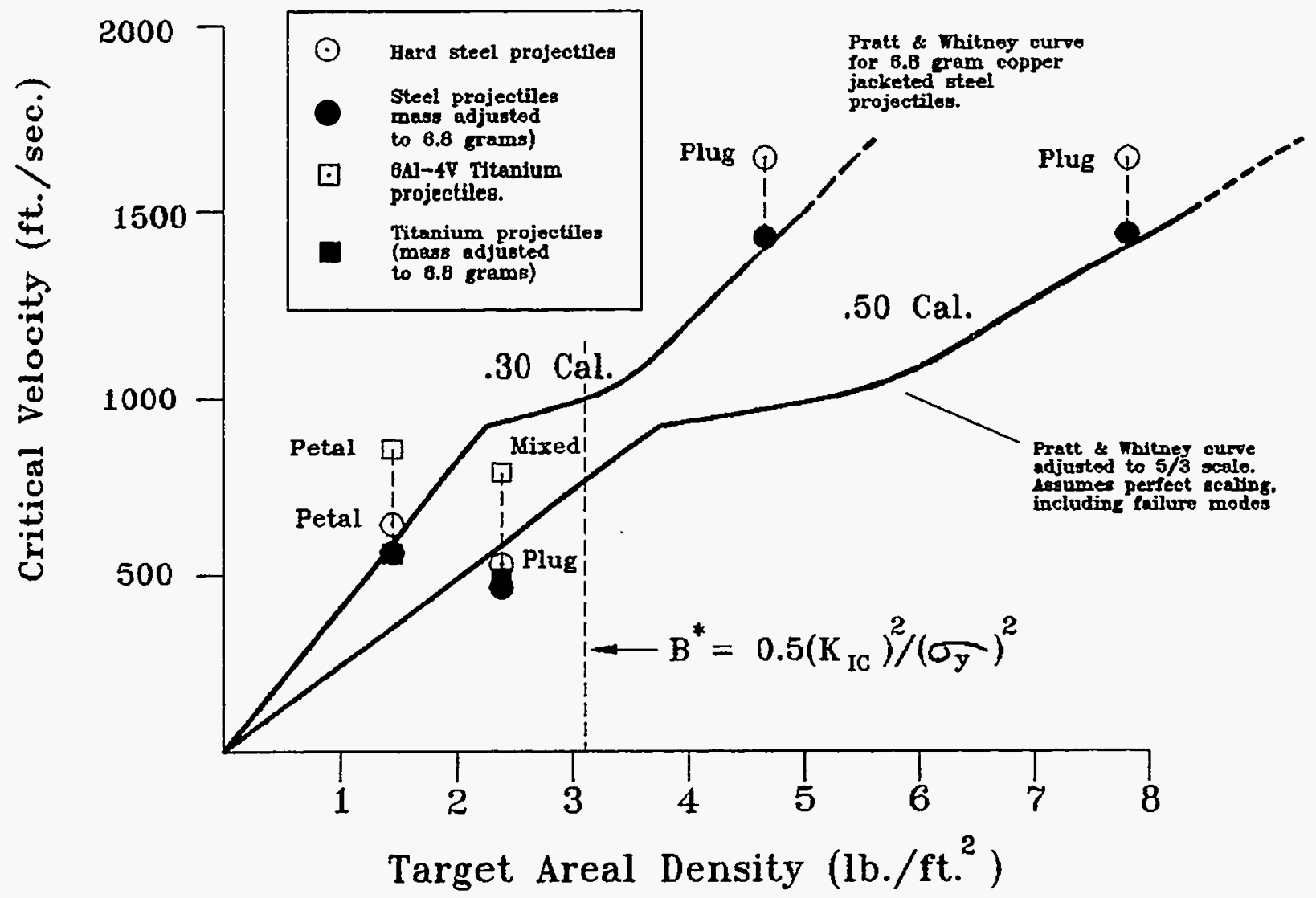

Figure 29. Data for 0.25-in.- and 0.42-in.-diameter steel and titanium projectiles impacting 6Al-4V titanium plates. (Pratt \& Whitney data included for reference.) 
masses of these projectiles are about 24 and $13.7 \mathrm{~g}$, respectively. Adjusting the mass of the projectiles to that of the .50-caliber, copperjacketed, steel-cored projectiles in the same way that we did for the .30-caliber projectiles, we compare our experimental data with the assumed perfectly scaled .50-caliber copper-jacketed projectile relationship. The closed symbols adjacent to the .50-caliber relationship of Fig. 29 are the result of this downward vertical adjustment of the projectile limit speeds.

At a target areal density of about 8 psf (corresponding to the higher steel projectile limit speed), the observed target failure mode is a shear-plug failure; this is the same as assumed for the copper-jacketed projectile. Agreement between our experimental data and the assumed perfect geometrically scaled relationship is quite good. Furthermore, the actual baseline scale and 5/3-scale projectile limit speeds against the corresponding titanium-plate targets are identi$\mathrm{cal}-1630 \mathrm{ft} / \mathrm{s}$ vs $1634 \mathrm{ft} / \mathrm{s}$. Therefore, we conclude that geometric scaling is valid.

At a target areal density of about 2.5 psf, we observe that projectile mass adjustment collapses the different limit speeds of the titanium and steel projectiles to about the same limit speed. However, the observed target failure modes are now "mixed" (titanium projectile) and shear plugging (steel projectile). At $2.5 \mathrm{psf}$, the failure mode associated with the perfectly scaled relationship is the petal mode. Furthermore, the observed target failure mode for our baselinescale experiments at the corresponding target areal density was a petal mode. Also, the corresponding projectile limit speeds at $5 / 3$ scale are lower than at baseline scale. On this basis, we conclude that geometric scaling from the baseline scale to $5 / 3$ scale is not valid, because the failure mode of the target changed.

A colleague of ours, John Reaugh, pointed out to us that the critical thickness $\left(B^{*}\right)$ of a plate for transition from a ductile to brittle mode of fracture associated with a propagating crack is

$$
\left.B^{*}=0.5\left(K_{\mathrm{IC}}\right)^{2} / \sigma_{\mathrm{y}}\right)^{2}
$$

where $K_{\mathrm{IC}}$ is the critical stress intensity factor, and $\sigma_{\mathrm{y}}$ is the tensile yield stress.

Ductile fracture occurs (plate thickness less than $B^{*}$ ) when there is a substantial plastic reduction of plate thickness ahead of the propagating crack. When the reduction in thickness is relatively small, the fracture is called brittle (plate thickness greater than $B^{*}$ ). Furthermore, the change in the nature of fracture occurs abruptly with change in plate thickness. ${ }^{*}$ Using "handbook" values for the mechanical properties of titanium, $B^{*}$ is calculated to be 0.135 in. or, expressed in terms of areal density, 3.1 psf. This critical thickness is of the same order as the thickness at which the transition occurs from a target plate petal mode of failure to a shear (plug) mode of failure (e.g., see Fig. 29).

We are concerned about the location of the failure transition point (region) as a function of geometric scale; i.e., is projectile limit speed at the critical plate thickness (transition from petal to shear plug failure) invariant with geometric scale?

The second result taken from the simple analytic model for shear plug failure (see Appen$\operatorname{dix}$ C) that we will use is as follows:

The nondimensional variables that describe shear-plug failure of metallic plates impacted by blunt rigid projectiles are

$$
\begin{aligned}
& (L / D)_{\text {projectile }} \\
& T_{\text {plate }} / D_{\text {projectile }} \\
& \rho_{\text {projectile }} / \rho_{\text {target }} \\
& \left(\rho^{*} V^{2}\right)_{\text {projectile }} /\left(\tau_{\text {shear }}\right)_{\text {target }}
\end{aligned}
$$

\author{
projectile fineness ratio \\ characteristic plate thickness \\ ratio of projectile to target densities \\ ratio of projectile dynamic stress \\ to target ultimate stress.
}

\footnotetext{
* "Fracture Mode Transition for a Crack Traversing a Plate," G. R. Irwin, J. Basic Engineering, Transactions of the ASME, June 1960.
} 
Figure 30 shows projectile limit speed as a function of the characteristic thickness of the target-both expressed in nondimensional terms. We have taken the Pratt \& Whitney data and expressed them in nondimensional form. Also, we have adjusted the projectile limit speeds upward by "reducing the mass" of the Pratt \& Whitney projectiles from 6.8 to $5.2 \mathrm{~g}$ (i.e., by "removing the copper jackets" from the Pratt \& Whitney projectiles. One would have a family of such relationships, as seen in Fig. 30, as a function of projectile fineness ratio; however, the data presented are for a projectile fineness ratio of 3.28.

\section{At a characteristic target plate thickness} $(T / D)$ of about 0.8 , the observed target failure mode is shear-plug formation for the baselineand 5/3-scale steel projectiles, which is in agreement with the Pratt \& Whitney data. At a $T / D$ of about 0.25 , the baseline steel and titanium projectiles produce a petal failure in the titanium plate targets near the limit speed and also are consistent and in agreement numerically with the Pratt \& Whitney data.

However, the observed mixed and shear failures of the 5/3-scale projectiles are different from the assumed perfectly scaled Pratt \& Whitney data in mode of failure and in projectile limit speed. If perfect geometric scaling were valid, we would have expected all the data at this characteristic target-plate thickness to have collapsed upon itself. A change in failure mode (either for the target or the projectile) as geometric scale changes - even when all other parameters and properties are preserved-means that the projectile limit speed may no longer be scale invariant. Here, the mode of target failure did change with scale, and the projectile limit speed did not remain constant.

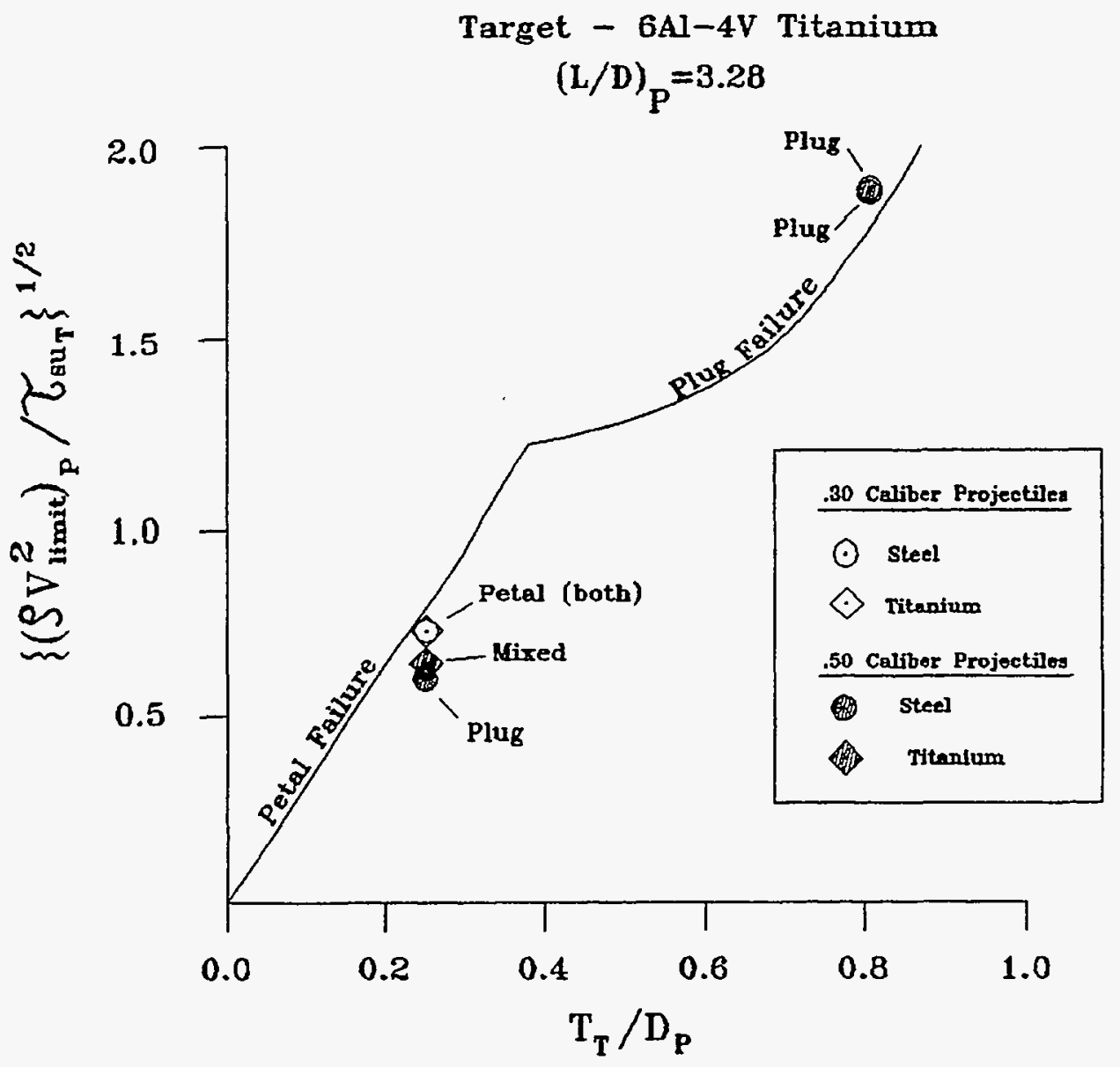

Figure 30. Ballistic data in nondimensional form. 
Appendix A

Ballistic Data

Table A1. Experimental results-titanium plate experiments

\begin{tabular}{|c|c|c|c|c|c|}
\hline Experiment & $\begin{array}{l}\text { Plate } \\
\text { Thickness } \\
\text { (in.) }\end{array}$ & $\begin{array}{l}\text { Pitch } \\
\text { (deg) }\end{array}$ & $\begin{array}{l}\text { Velocity } \\
(\mathrm{ft} / \mathrm{s})\end{array}$ & $\begin{array}{c}\text { Projectile } \\
\text { pass through? }\end{array}$ & Notes \\
\hline SST-23 & 0.176 & 0.8 & 1089 & No & \\
\hline SST-24 & 0.176 & 0.3 & 1175 & No & \\
\hline SST-25 & 0.176 & 1.1 & 1229 & Yes & $\begin{array}{l}\text { Penetration in witness was } \\
0.010 \text { in. }\end{array}$ \\
\hline SST-26 & 0.128 & 0.2 & 827 & No & \\
\hline SST-27 & 0.128 & 0.3 & 1040 & No & Projectile lodged in target. \\
\hline SST-28 & 0.083 & 0.9 & 692 & No & \\
\hline SST-29 & 0.082 & 0.0 & 849 & Yes & $\begin{array}{l}\text { Penetration in witness was } \\
0.049 \text { in. }\end{array}$ \\
\hline SST-30 & 0.084 & 1.3 & 743 & No & Target cracked. \\
\hline SST-31 & 0.066 & 4.4 & 338 & No & $\begin{array}{l}\text { Questionable-excessive } \\
\text { pitch. }\end{array}$ \\
\hline SST-32 & 0.066 & 0.7 & 684 & No & $\begin{array}{l}\text { Projectile perforated target } \\
\text { but did not pass through. }\end{array}$ \\
\hline SST-33 & 0.066 & 0.6 & 493 & No & \\
\hline SST-34 & 0.066 & 0.0 & 685 & No & $\begin{array}{l}\text { Projectile perforated target } \\
\text { but did not pass through. }\end{array}$ \\
\hline
\end{tabular}


Table A2. Experimental results-select metallic targets.

\begin{tabular}{|c|c|c|c|c|}
\hline Experiment & Target & $\begin{array}{l}\text { Velocity } \\
(\mathrm{ft} / \mathrm{s})\end{array}$ & Result & $\begin{array}{c}\text { Resid, into } \\
\text { 3/4-in. 6061-T6 }\end{array}$ \\
\hline SST-84 & $\begin{array}{l}3 \text { pieces } 0.088 \text {-in. } \\
6061-\mathrm{T} 6 \mathrm{Al} \text {, } \\
\text { stacked, clamped }\end{array}$ & 706 & Did not perforate & - \\
\hline SST-85 & $\begin{array}{l}3 \text { pieces } 0.076 \text {-in. } \\
11 \text { layers } 5182 \\
\text { alt. with } 10 \text { layers } \\
6090+S i C \text { part. }\end{array}$ & 810 & Perforated & 0.010 \\
\hline SST-86 & $\begin{array}{l}3 \text { pieces } 0.076 \text {-in. } \\
11 \text { layers } 5182 \\
\text { alt. with } 10 \text { layers } \\
6090+\mathrm{SiC} \text { part. }\end{array}$ & 759 & Perforated & 0.0 \\
\hline SST-87 & $\begin{array}{l}3 \text { pieces } 0.076 \text {-in. } \\
11 \text { layers } 5182 \\
\text { alt. with } 10 \text { layers } \\
6090+\mathrm{SiC} \text { part. }\end{array}$ & 698 & Did not perforate & - \\
\hline SST-88 & $\begin{array}{l}3 \text { pieces } 0.088 \text {-in. } \\
6061-\mathrm{T} 6 \mathrm{Al} \\
\text { stacked, clamped }\end{array}$ & 729 & Did not perforate & - \\
\hline SST-89 & $\begin{array}{l}3 \text { pieces } 0.088 \text {-in. } \\
6061-\mathrm{T} 6 \mathrm{Al} \\
\text { stacked, clamped }\end{array}$ & 903 & Did not perforate & - \\
\hline SST-90 & $\begin{array}{l}3 \text { pieces } 0.088 \text {-in. } \\
6061-\mathrm{T} 6 \mathrm{Al} \\
\text { stacked, clamped }\end{array}$ & 1052 & Perforated & 0.018 \\
\hline SST-91 & $\begin{array}{l}\text { One piece } 0.264 \text {-in. } \\
6061-\mathrm{T} 6 \mathrm{Al}\end{array}$ & 890 & Perforated & 0.019 \\
\hline SST-92 & $\begin{array}{l}\text { One piece 0.264-in. } \\
\text { 6061-T6 A1 }\end{array}$ & 750 & Did not perforate & - \\
\hline SST-93 & $\begin{array}{l}\text { One piece 0.264-in. } \\
6061-\mathrm{T} 6 \mathrm{Al}\end{array}$ & 778 & Perforated & 0.0 \\
\hline SST-94 & $\begin{array}{l}3 \text { pieces } 0.095 \text {-in. } \\
5182 \mathrm{Al} \\
\text { (as received) } \\
\text { stacked, clamped }\end{array}$ & 650-est. & Did not perforate & - \\
\hline SST-96 & $\begin{array}{l}3 \text { pieces } 0.095 \text {-in. } \\
5182 \text { Aluminum } \\
\text { (as received) } \\
\text { stacked, clamped }\end{array}$ & 840 & Did not perforate & - \\
\hline SST-97 & $\begin{array}{l}3 \text { pieces } 0.095 \text {-in. } \\
5182 \mathrm{Al} \\
\text { (as received) } \\
\text { stacked, clamped }\end{array}$ & 1049 & Perforated & 0.036 \\
\hline SST-98 & $\begin{array}{l}3 \text { pieces } 0.095-\text { in. } \\
5182 \mathrm{Al} \\
\text { (as received) } \\
\text { stacked, clamped }\end{array}$ & 988 & Did not perforate & - \\
\hline
\end{tabular}


Table A2. Experimental results--select metallic targets (continued).

\begin{tabular}{|c|c|c|c|c|}
\hline Experiment & Target & $\begin{array}{l}\text { Velocity } \\
(\mathrm{ft} / \mathrm{s})\end{array}$ & Result & $\begin{array}{c}\text { Resid, into } \\
\text { 3/4-in. 6061-T6 }\end{array}$ \\
\hline SST-99 & $\begin{array}{l}3 \text { pieces } 0.095 \text {-in. } \\
5182 \text { Aluminum } \\
\text { (heat-treated) } \\
\text { stacked, clamped }\end{array}$ & 949 & Did not perforate & - \\
\hline SST-100 & $\begin{array}{l}3 \text { pieces 0.095-in. } \\
5182 \mathrm{Al} \\
\text { (heat-treated) } \\
\text { stacked, clamped }\end{array}$ & 1065 & Perforated & 0.006 \\
\hline SST-101 & $\begin{array}{l}3 \text { pieces } 0.095-\text { in. } \\
5182 \mathrm{Al} \\
\text { (heat-treated) } \\
\text { stacked, clamped }\end{array}$ & 1049 & Perforated & 0.034 \\
\hline SST-102 & $\begin{array}{l}3 \text { pieces } 0.095-\mathrm{in} \text {. } \\
5182 \mathrm{Al} \\
\text { (heat-treated) } \\
\text { stacked, clamped }\end{array}$ & 1058 & Perforated & 0.005 \\
\hline SST-103 & $\begin{array}{l}3 \text { pieces } 0.115-i n \text {. } \\
6090 / \mathrm{SiC}(25 \%) \\
\text { (as received) } \\
\text { stacked, clamped }\end{array}$ & 918 & Did not perforate & - \\
\hline SST-104 & $\begin{array}{l}3 \text { pieces } 0.115 \text {-in. } \\
6090 / \mathrm{SiC}(25 \%) \\
\text { (as received) } \\
\text { stacked, clamped }\end{array}$ & 1001 & Did not perforate & - \\
\hline SST-105 & $\begin{array}{l}3 \text { pieces } 0.115-i n \text {. } \\
6090 / \mathrm{SiC}(25 \%) \\
\text { (as received) } \\
\text { stacked, clamped }\end{array}$ & 1059 & Perforated & 0.014 \\
\hline SST-106 & $\begin{array}{l}3 \text { pieces } 0.115 \text {-in. } \\
6090 / \mathrm{SiC}(25 \%) \\
\text { (as received) } \\
\text { stacked, clamped }\end{array}$ & 941 & Did not perforate & - \\
\hline SST-107 & $\begin{array}{l}3 \text { pieces } 0.115 \text {-in. } \\
6090 / \mathrm{SiC}(25 \%) \\
\text { (as received) } \\
\text { stacked, clamped }\end{array}$ & 1045 & Did not perforate & - \\
\hline SST-108 & $\begin{array}{l}3 \text { pieces } 0.115 \text {-in. } \\
6090 / \text { SiC }(25 \%) \\
\text { (as received) } \\
\text { stacked, clamped }\end{array}$ & 1134 & Did not perforate & - \\
\hline SST-109 & $\begin{array}{l}3 \text { pieces } 0.115 \text {-in. } \\
6090 / \mathrm{SiC}(25 \%) \\
\text { (as received) } \\
\text { stacked, clamped }\end{array}$ & 1218 & Perforated & 0.0 \\
\hline
\end{tabular}


Table A2. Experimental results-select metallic targets (continued).

\begin{tabular}{|c|c|c|c|c|}
\hline Experiment & Target & $\begin{array}{l}\text { Velocity } \\
(\mathrm{ft} / \mathrm{s})\end{array}$ & Result & $\begin{array}{c}\text { Resid, into } \\
\text { 3/4-in. 6061-T6 }\end{array}$ \\
\hline SST110 & $\begin{array}{l}\text { One piece, } 0.385 \mathrm{in} . \\
\text { thick, } 11 \text { layers } \\
5182 \mathrm{Al} \text { alt. } \\
\text { with } 10 \text { layers } \\
6090+\mathrm{SiC} \text { part. } 25 \% \\
\text { (as pressed) }\end{array}$ & 1184 & Perforated & 0.003 \\
\hline SST-111 & $\begin{array}{l}\text { One piece, } 0.440 \mathrm{in} \text {. } \\
\text { thick, } 11 \text { layers } \\
5182 \mathrm{Al} \text { alt. } \\
\text { with } 10 \text { layers } \\
6090+\mathrm{SiC} \text { part. } 25 \% \\
\text { (as pressed) }\end{array}$ & 1244 & Did not perforate & - \\
\hline SST-112 & $\begin{array}{l}\text { One piece, } 0.440 \text { in. } \\
\text { thick, } 11 \text { layers } \\
5182 \mathrm{Al} \text { alt. } \\
\text { with } 10 \text { layers } \\
6090+\mathrm{SiC} \text { part. } 25 \% \\
\text { (as pressed) }\end{array}$ & 1366 & Perforated & 0.010 \\
\hline SST-113 & $\begin{array}{l}\text { One piece, } 0.440 \text { in. } \\
\text { thick, } 11 \text { layers } \\
5182 \mathrm{Al} \text { alt. } \\
\text { with } 10 \text { layers } \\
6090+\mathrm{SiC} \text { part. } 25 \% \\
\text { (as pressed) }\end{array}$ & 1307 & Perforated & 0.027 \\
\hline SST-114 & $\begin{array}{l}\text { One piece, } 0.427 \mathrm{in} . \\
\text { thick, } 11 \text { layers } \\
5182 \mathrm{Al} \\
\text { alt. with } 10 \text { layers } \\
6090+\mathrm{SiC} \text { part. } 25 \% \\
\text { (heat-treated) }\end{array}$ & 1337 & Perforated & 0.010 \\
\hline SST-115 & $\begin{array}{l}\text { One piece, } 0.427 \text { in. } \\
\text { thick, } 11 \text { layers } \\
5182 \mathrm{Al} \text { alt. } \\
\text { with } 10 \text { layers } \\
6090+\text { SiC part. } 25 \% \\
\text { (heat-treated) }\end{array}$ & 1233 & Did not perforate & - \\
\hline SST-116 & $\begin{array}{l}\text { One piece, } 0.427 \text { in. } \\
\text { thick, } 11 \text { layers } \\
5182 \mathrm{Al} \text { alt. } \\
\text { with } 10 \text { layers } \\
6090+\text { SiC part. } 25 \% \\
\text { (heat-treated) }\end{array}$ & 1246 & Did not perforate & - \\
\hline SST-117 & $\begin{array}{l}\text { One piece, } 0.427 \text { in. } \\
\text { thick, } 11 \text { layers } \\
5182 \mathrm{Al} \text { alt. } \\
\text { with } 10 \text { layers } \\
6090+\text { SiC part. } 25 \% \\
\text { (heat-treated) }\end{array}$ & 1288 & Perforated & 0.014 \\
\hline
\end{tabular}


Table A2. Experimental results-select metallic targets (continued).

\begin{tabular}{|c|c|c|c|c|}
\hline Experiment & Target & $\begin{array}{c}\text { Velocity } \\
\text { (ft/s) }\end{array}$ & Result & $\begin{array}{c}\text { Resid, into } \\
\text { 3/4-in. 6061-T6 }\end{array}$ \\
\hline SST-118 & $\begin{array}{l}\text { One piece, } 0.445 \text { in. } \\
\text { thick, } 11 \text { layers } \\
5182 \mathrm{Al} \text { alt. } \\
\text { with } 10 \text { layers } \\
6090+\text { SiC part. } 25 \% \text {; } \\
2 \text {-in. } \times 2 \text {-in. central } \\
\text { region of each layer } \\
\text { not descaled prior } \\
\text { to bonding }\end{array}$ & 1298 & Did not perforate & - \\
\hline SST-120 & $\begin{array}{l}3 \text { pieces, } 0.063-\mathrm{in} . \\
\text { Grade } 4 \mathrm{Ti} \\
\text { stacked, clamped }\end{array}$ & 1254 & $\begin{array}{l}\text { Perforated but did } \\
\text { not pass through; } \\
\text { stuck in target }\end{array}$ & - \\
\hline SST-121 & $\begin{array}{l}3 \text { pieces, } 0.063 \text {-in. } \\
\text { Grade } 4 \mathrm{Ti} \\
\text { stacked, clamped }\end{array}$ & 1339 & Perforated & 0.029 \\
\hline SST-122 & $\begin{array}{l}3 \text { pieces, } 0.063 \text {-in. } \\
\text { Grade } 4 \mathrm{Ti} \\
\text { stacked, clamped }\end{array}$ & 1360 & Perforated & 0.020 \\
\hline SST-123 & $\begin{array}{l}3 \text { pieces, } 0.063 \text {-in. } \\
\text { Grade } 4 \text { Ti } \\
\text { stacked, clamped }\end{array}$ & 1316 & Perforated & 0.021 \\
\hline SST-124 & $\begin{array}{l}3 \text { pieces, } 0.063 \text {-in. } \\
\text { 6Al-4V Ti } \\
\text { stacked, clamped }\end{array}$ & 1221 & Did not perforate & - \\
\hline SST-125 & $\begin{array}{l}3 \text { pieces, } 0.063-i n . \\
6 \mathrm{Al}-4 \mathrm{~V} \text { Ti } \\
\text { stacked, clamped }\end{array}$ & 1332 & $\begin{array}{l}\text { Perforated but did } \\
\text { not pass through; } \\
\text { stuck in target }\end{array}$ & - \\
\hline SST-126 & $\begin{array}{l}3 \text { pieces, } 0.063-i n . \\
6 \mathrm{Al}-4 \mathrm{~V} \mathrm{Ti} \\
\text { stacked, clamped }\end{array}$ & 1343 & Perforated & 0.0 \\
\hline SST-127 & $\begin{array}{l}1 \text { piece, } 0.251-i n . \\
\text { thick, } 7075-T 6 \\
\text { aluminum }\end{array}$ & 875 & $\begin{array}{l}\text { Perforated but did } \\
\text { not pass through; } \\
\text { stuck in target }\end{array}$ & - \\
\hline SST-128 & $\begin{array}{l}1 \text { piece, } 0.251 \text { in. } \\
\text { thick, } 7075-T 6 \\
\text { aluminum }\end{array}$ & 917 & $\begin{array}{l}\text { Perforated but did } \\
\text { not pass through; } \\
\text { stuck in target }\end{array}$ & - \\
\hline SST-129 & $\begin{array}{l}1 \text { piece, } 0.251 \text { in. } \\
\text { thick, } 7075-T 6 \\
\text { aluminum }\end{array}$ & 1026 & $\begin{array}{l}\text { Perforated but did } \\
\text { not pass through; } \\
\text { stuck in target }\end{array}$ & - \\
\hline SST-130 & $\begin{array}{l}1 \text { piece, } 0.251 \text { in. } \\
\text { thick, } 7075-T 6 \\
\text { aluminum }\end{array}$ & 1228 & Perforated & 0.005 \\
\hline SST-131 & $\begin{array}{l}1 \text { piece, } 0.251 \text { in. } \\
\text { thick, } 7075-\mathrm{T} 6 \\
\text { aluminum }\end{array}$ & 1081 & $\begin{array}{l}\text { Perforated but did } \\
\text { not pass through; } \\
\text { stuck in target }\end{array}$ & - \\
\hline
\end{tabular}


Table A2. Experimental results-select metallic targets (continued).

\begin{tabular}{|c|c|c|c|c|}
\hline Experiment & Target & $\begin{array}{l}\text { Velocity } \\
(\mathrm{ft} / \mathrm{s})\end{array}$ & Result & $\begin{array}{c}\text { Resid, into } \\
\text { 3/4-in. 6061-T6 }\end{array}$ \\
\hline SST-132 & $\begin{array}{l}3 \text { pieces, } 0.090-\mathrm{in} . \\
\text { 7075-T6 Al } \\
\text { stacked, clamped }\end{array}$ & 1121 & Perforated & 0.028 \\
\hline SST-133 & $\begin{array}{l}3 \text { pieces, } 0.090 \text {-in. } \\
\text { 7075-T6 Al } \\
\text { stacked, clamped }\end{array}$ & 1069 & $\begin{array}{l}\text { Perforated but did } \\
\text { not pass through; } \\
\text { stuck in target }\end{array}$ & 一 \\
\hline SST-134 & $\begin{array}{l}\text { One piece, } 0.253 \text {-in. } \\
6090 / \mathrm{SiC}(25 \%) \\
\text { (heat-treated) }\end{array}$ & 803 & $\begin{array}{l}\text { Perforated but did } \\
\text { not pass through; } \\
\text { stuck in target }\end{array}$ & - \\
\hline SST-135 & $\begin{array}{l}\text { One piece, } 0.253 \text {-in. } \\
6090 / \mathrm{SiC}(25 \%) \\
\text { (heat-treated) }\end{array}$ & 980 & $\begin{array}{l}\text { Perforated but did } \\
\text { not pass through; } \\
\text { stuck in target }\end{array}$ & - \\
\hline SST-136 & $\begin{array}{l}\text { One piece, } 0.253 \text {-in. } \\
6090 / \mathrm{SiC}(25 \%) \\
\text { (heat-treated) }\end{array}$ & 1091 & $\begin{array}{l}\text { Perforated but did } \\
\text { not pass through; } \\
\text { stuck in target }\end{array}$ & - \\
\hline SST-137 & $\begin{array}{l}\text { One piece, } 0.253 \text {-in. } \\
6090 / \mathrm{SiC}(25 \%) \\
\text { (heat-treated) }\end{array}$ & 1177 & Perforated & 0.0 \\
\hline SST-138 & $\begin{array}{l}\text { One piece, } 0.063 \text {-in. } \\
\text { Grade } 4 \mathrm{Ti}\end{array}$ & 573 & Did not perforate & - \\
\hline SST-139 & $\begin{array}{l}\text { One piece, } 0.063 \text {-in. } \\
\text { Grade } 4 \mathrm{Ti}\end{array}$ & 635 & Did not perforate & - \\
\hline SST-140 & $\begin{array}{l}\text { One piece, 0.063-in. } \\
\text { Grade } 4 \mathrm{Ti}\end{array}$ & 800 & Perforated & 0.020 \\
\hline SST-141 & $\begin{array}{l}\text { One piece, 0.063-in. } \\
\text { Grade } 4 \mathrm{Ti}\end{array}$ & 801 & Perforated & 0.033 \\
\hline SST-142 & $\begin{array}{l}\text { One piece, 0.063-in. } \\
\text { Grade } 4 \mathrm{Ti}\end{array}$ & 626 & Did not perforate & - \\
\hline SST-143 & $\begin{array}{l}\text { One piece, 0.063-in. } \\
\text { Grade } 4 \mathrm{Ti}^{\mathbf{1}}\end{array}$ & 712 & Perforated & 0.0 \\
\hline
\end{tabular}


Table A3. Ballistic data-Baseline-scale (.30-caliber) experiments.

\begin{tabular}{|c|c|c|c|c|c|}
\hline Experiment & $\begin{array}{l}\text { Velocity } \\
\text { (ft/s) }\end{array}$ & $\begin{array}{c}\text { Perforated? } \\
\text { Y/N }\end{array}$ & $\begin{array}{c}\text { Residual } \\
\text { (in.) }\end{array}$ & $\begin{array}{l}\text { Pitch } \\
\text { (deg) }\end{array}$ & Comment \\
\hline \multicolumn{6}{|c|}{0.062 -in. target, steel projectile } \\
\hline SST-53 & 950 & $\mathrm{Y}$ & 0.062 & $<0.5$ & \\
\hline SST-54 & 671 & $\mathbf{Y}$ & 0 & $<0.5$ & \\
\hline SST-55 & 543 & $\mathbf{N}$ & - & 1.5 & \\
\hline \multicolumn{6}{|c|}{0.202 -in. target, steel projectile } \\
\hline SST-56 & 1388 & $\mathbf{N}$ & - & $<0.5$ & \\
\hline SST-57 & 1590 & $\mathbf{N}$ & - & $<0.5$ & \\
\hline SST-58 & - & $\mathbf{Y}$ & 0.010 & $?$ & $X$ ray failed \\
\hline SST-59 & 1669 & $\mathbf{Y}$ & 0.026 & 1.0 & Soft steel witness plate \\
\hline \multicolumn{6}{|c|}{ 0.062-in. target, titanium projectile } \\
\hline SST-60 & 1041 & $\mathbf{Y}$ & 0.047 & $<0.5$ & \\
\hline SST-61 & 720 & $\mathbf{N}$ & - & $<0.5$ & \\
\hline SST-62 & 976 & $Y$ & 0.026 & 1.0 & \\
\hline SST-63 & 587 & $\mathbf{N}$ & - & 2.2 & \\
\hline SST-64 & 902 & $\mathrm{Y}$ & 0.016 & 1.5 & \\
\hline SST-65 & 795 & $\mathbf{N}$ & & 1.0 & \\
\hline \multicolumn{6}{|c|}{ 0.202-in. target, titanium projectile } \\
\hline SST-66 & 1760 & $\mathbf{N}$ & - & 1.6 & \\
\hline SST-67 & 2058 & $\mathbf{N}$ & - & - & Not close to perforation \\
\hline
\end{tabular}


Table A4. Ballistic data-5/3-scale (.50-caliber) experiments.

\begin{tabular}{|c|c|c|c|c|c|}
\hline Experiment & $\begin{array}{c}\text { Velocity } \\
\text { (ft/s) }\end{array}$ & $\begin{array}{c}\text { Perforated? } \\
\mathrm{Y} / \mathrm{N} \\
\end{array}$ & $\begin{array}{l}\text { Residual } \\
\text { (in.) }\end{array}$ & $\begin{array}{l}\text { Pitch } \\
\text { (deg) }\end{array}$ & Comment \\
\hline \multicolumn{6}{|c|}{ 102-in. target, steel projectile } \\
\hline SST-35 & 1176 & $\mathbf{Y}$ & 0.223 & 0.7 & \\
\hline SST-36 & 503 & $\mathbf{N}$ & - & 0.8 & \\
\hline SST-37 & 748 & $\mathbf{Y}$ & 0.095 & $<0.5$ & \\
\hline SST-38 & 711 & $\mathbf{Y}$ & 0.120 & $<0.5$ & \\
\hline SST-39 & 688 & $\mathbf{Y}$ & 0.072 & $<0.5$ & \\
\hline SST-40 & 567 & $Y$ & 0.018 & 0.7 & \\
\hline \multicolumn{6}{|c|}{ 0.335-in. target, steel projectile } \\
\hline SST-41 & 1291 & $\mathbf{N}$ & - & $<0.5$ & \\
\hline SST-42 & 1337 & $\mathbf{N}$ & - & $<0.5$ & \\
\hline SST-83 & 1683 & $\mathrm{Y}$ & 0.105 & 1.4 & \\
\hline SST-84 & 1570 & $\mathbf{N}$ & 一 & $<0.5$ & \\
\hline SST-85 & 1585 & $\mathbf{N}$ & - & $<0.5$ & \\
\hline SST-86 & 1573 & $\mathbf{N}$ & - & $<0.5$ & \\
\hline \multicolumn{6}{|c|}{0.102 -in. target, titanium projectile } \\
\hline SST-75 & 706 & $\mathbf{N}$ & - & 17.0 & Experiment not valid \\
\hline SST-76 & 944 & $\mathbf{Y}$ & 0.125 & 0.8 & \\
\hline SST-77 & 864 & $\mathbf{Y}$ & 0.084 & $<0.5$ & \\
\hline SST-78 & 646 & $\mathbf{N}$ & - & $<0.9$ & \\
\hline SST-79 & 682 & $\mathbf{N}$ & - & 2.2 & \\
\hline
\end{tabular}




\section{Appendix B \\ Estimate of Ballistic Limit Speeds}

\begin{tabular}{cc} 
Table B1. Ballistic limits-titanium plate experiments. \\
\hline Plate thickness (in.) & Limit velocity (ft/s) \\
\hline 0.176 & 1202 \\
0.128 & $1040(+) *$ \\
0.083 & 796 \\
0.066 & $685(+) * *$ \\
\hline
\end{tabular}

* From experiment SST-27.

** From experiments SST-33 and SST-34.

$(+)$ Indicates the true limit velocity is slightly above the value given.

Table B2. Ballistic limits-select metallic targets.

Target Limit velocity $(\mathrm{ft} / \mathrm{s})$

One piece 0.264-in.-thick 6061-T6 Al $764 \pm 19$

One piece, $0.440 \mathrm{in}$. thick, 10 layers $5182 \mathrm{Al}$ alt. with 9 $1276 \pm 32$

layers $6090+\mathrm{SiC}(25 \%)$ (as pressed), stacked and clamped

One piece, 0.427 in. thick, 10 layers 5182 alt. with 9 layers $1267 \pm 21$

$6090+\operatorname{SiC}(25 \%)$ (heat-treated), stacked and clamped

One piece, 0.251-in.-thick 7075-T6 Al $1155 \pm 74$

One piece, 0.253-in.-thick 6090/SiC (25\%) (heat-treated)

$1134 \pm 43$

One piece, 0.063-in.-thick Grade 4 Ti

$674 \pm 39$

3 pieces, 0.088-in.-thick 6061-T6 $\mathrm{Al}$, stacked and clamped

$978 \pm 75$

3 pieces, 0.095 -in.-thick $5182 \mathrm{Al}$ (as received), stacked and clamped

$1019 \pm 31$

3 pieces, 0.095-in.-thick $5182 \mathrm{Al}$ (heat-treated), stacked and clamped

$999 \pm 50$

3 pieces, 0.115-in.-thick 6090/SiC (25\%) (as received), stacked and clamped

$1030 \pm 29$

3 pieces, 0.115-in.-thick 6090/SiC (25\%) (heat-treated), stacked and clamped

$1176 \pm 42$

3 pieces, 0.076-in.-thick, each piece 11 layers $5182 \mathrm{Al}$

$729 \pm 31$

alt. with 10 layers $6090+\mathrm{SiC}(25 \%)$, stacked and clamped

$1285 \pm 31$

3 pieces, 0.063 -in.-thick Grade $4 \mathrm{Ti}$, stacked, clamped

$1338 \pm 6$

3 pieces, 0.063 -in-thick $6 \mathrm{Al}-4 \mathrm{~V} \mathrm{Ti}$, stacked, clamped

$1095 \pm 26$

3 pieces, 0.090-in.-thick 7075-T6 Al, stacked, clamped 
Table B3. Ballistic limit speeds.

\begin{tabular}{|c|c|c|c|c|}
\hline Target & Projectile & $\begin{array}{l}\text { Limit velocity } \\
(\mathrm{ft} / \mathrm{s})\end{array}$ & $\begin{array}{c}\text { Biased limit speed } \\
(\mathrm{ft} / \mathrm{s})\end{array}$ & $\begin{array}{c}\text { Failure mode } \\
\text { Near B.L. }\end{array}$ \\
\hline \multicolumn{5}{|c|}{ Baseline-scale (.30-caliber) experiments } \\
\hline $0.062 \mathrm{in}$. & Steel & $607 \pm 64)$ & 639 & Petal \\
\hline 0.202 in. & Steel & $1630 \pm 40$ & - & Plug \\
\hline $0.062 \mathrm{in.}$ & Titanium & $849 \pm 54$ & - & Petal \\
\hline \multicolumn{5}{|c|}{ 5/3-scale (.50-caliber) experiments } \\
\hline $0.102 \mathrm{in}$. & Steel & $535 \pm 32$ & - & Plug \\
\hline $0.335 \mathrm{in}$. & Steel & $1634 \pm 49$ & 一 & Plug \\
\hline 0.102 in. & Titanium & $773 \pm 91$ & 728 & Mixed \\
\hline
\end{tabular}




\section{Appendix C \\ A Simple Model for Thin-Plate Shear-Plug Failure}

Assume:

1. A projectile traveling at speed $V$ impacts a plate of thickness $T_{\text {plate }}$ normally; i.e., the projectile velocity is parallel to the plate perpendicular.

2. The projectile's geometry is a right circular cylinder of diameter $D_{\mathrm{p}}$ and length $L_{\mathrm{p}}$. The average density of the projectile is $\rho_{\mathrm{p}}$. The mass of the projectile $m_{\mathrm{p}}$ is, therefore,

$$
m_{\mathrm{p}}=\rho_{\mathrm{p}} \cdot\left(\frac{\pi}{4}\right) \cdot D_{\mathrm{p}}^{3} \cdot\left(\frac{L}{D}\right)_{\mathrm{p}}
$$

3. The projectile is rigid during its interaction with the plate, i.e. it neither deforms nor loses mass.

4. The plate consists of a homogeneous, isotropic material of large lateral extent in comparison to the projectile diameter and is relatively thin; i.e., the ratio of the plate thickness to projectile diameter is small. The ultimate shear strength of the plate material is constant.

5. During the interaction of projectile and target, a "plug" is formed in the plate directly under the projectile; i.e., the plate experiences a shear failure. The geometry of the plug is a right circular cylinder. The diameter of the plug is slightly larger than the diameter of the projectile. The length of the plug is the plate thickness.

6. The projectile impact speed and the thickness of the plate are such that the projectile and the plug are at rest at termination of the interaction.

On this basis, the change in kinetic energy of the projectile during the interaction equals the work done on the plate by the projectile to form the plug:

$\frac{1}{2} \cdot m_{\mathrm{p}} \cdot V_{\mathrm{p}}^{2}=W=F_{\text {shear }} \cdot T_{\text {plate }}$

where $F_{\text {shear }}$ is the average shear force needed to form the plug, or

$\frac{1}{2} \cdot\left(\frac{\pi}{4}\right) \cdot \rho_{\mathrm{p}} \cdot D_{\mathrm{p}}^{3} \cdot\left(\frac{L}{D}\right)_{\mathrm{p}} \cdot V^{2}=\tilde{\tau}_{\text {shear }} \cdot\left[\alpha \cdot \pi \cdot D_{\mathrm{p}} \cdot T_{\text {plate }}\right] \cdot T_{\text {plate }}$

where $\tilde{\tau}_{\text {shear }}$ is the average plate shear stress required to form the plug and $\alpha$ is the constant of proportionality formed by taking the ratio of the average plug diameter to the projectile diameter.

Simplifying the above:

$\frac{1}{8} \cdot \rho_{\mathrm{p}} \cdot D_{\mathrm{p}}^{2} \cdot\left(\frac{L}{D}\right)_{\mathrm{p}} \cdot V^{2}=\tilde{\tau}_{\text {shear }} \cdot \alpha \cdot T_{\mathrm{plate}}^{2}$ 
where $\tilde{\tau}_{\text {shear }}=\beta \cdot \tau_{\mathrm{su}}$ with $\beta$ as a constant of proportionality and $\tau_{\text {su }}$ as the ultimate shear stress of the plate material.

Then, in nondimensional form,

$\frac{\rho_{\text {projectile }} V^{2}}{\tau_{\text {su }}}=\left(\rho_{\mathrm{p}} / \rho_{\mathrm{T}}\right) \cdot \frac{V^{2}}{\tau_{\text {su }} / \rho_{\text {target }}}$

where $C$ is a constant to be determined from experiment.

In nondimensional form, the variables that describe the formation of plate shear failure under ballistic impact are

a. $T_{\text {plate }} / D_{\text {projectile }}$

which describes the "thickness" of the target plate relative to the projectile.

b. $\quad(L / D)_{\text {projectile }}$

which describes the geometry of the projectile.

c. $\quad \frac{V^{2}}{\tau_{\mathrm{su}} / \rho_{\text {projectile }}}=\left(\rho_{\mathrm{p}} / \rho_{\mathrm{T}}\right) \cdot \frac{V^{2}}{\tau_{\mathrm{su}} / \rho_{\text {target }}}$,

which is the projectile dynamic pressure divided by the plate shear resistance.

d. $\quad \rho_{\mathrm{p}} / \rho_{\mathrm{t}}$,

which is the ratio of projectile-to-target densities. 